University of Wollongong

Research Online

Faculty of Engineering and Information

Faculty of Engineering and Information

Sciences - Papers: Part A

Sciences

$1-1-2016$

Computational fluid dynamics simulation of carbon dioxide dispersion in a complex environment

\author{
Bin Liu \\ University of Wollongong, bl384@uowmail.edu.au \\ Xiong Liu \\ University of Wollongong, xiong@uow.edu.au \\ Cheng Lu \\ University of Wollongong, chenglu@uow.edu.au \\ Ajit R. Godbole \\ University of Wollongong, agodbole@uow.edu.au \\ Guillaume Michal \\ University of Wollongong,gmichal@uow.edu.au
}

See next page for additional authors

Follow this and additional works at: https://ro.uow.edu.au/eispapers

Part of the Engineering Commons, and the Science and Technology Studies Commons

Research Online is the open access institutional repository for the University of Wollongong. For further information contact the UOW Library: research-pubs@uow.edu.au 


\title{
Computational fluid dynamics simulation of carbon dioxide dispersion in a complex environment
}

\author{
Abstract \\ In order to quantitatively evaluate the risk associated with the Carbon Capture and Storage (CCS) \\ technology, a deeper understanding of $\mathrm{CO} 2$ dispersion resulting from accidental releases is essential. \\ $\mathrm{CO} 2$ is a heavier-than-air gas. Its dispersion patterns may vary according to local conditions. This study \\ focuses on $\mathrm{CO} 2$ dispersion over complex terrains. Computational Fluid Dynamics (CFD) models were \\ developed to simulate the $\mathrm{CO} 2$ dispersion over two hypothetical topographies: (1) a flat terrain with an \\ axisymmetric hill and (2) a simplified model of an urban area with buildings. The source strength, wind \\ velocity and height of the buildings were varied to investigate their effects on the dispersion profile. The \\ study may offer a viable method for assessment of risks associated with CCS.

\section{Disciplines} \\ Engineering | Science and Technology Studies

\section{Publication Details} \\ Liu, B., Liu, X., Lu, C., Godbole, A., Michal, G. \& Tieu, A. Kiet. (2016). Computational fluid dynamics \\ simulation of carbon dioxide dispersion in a complex environment. Journal of Loss Prevention in the \\ Process Industries, 40 419-432.

\section{Authors} \\ Bin Liu, Xiong Liu, Cheng Lu, Ajit R. Godbole, Guillaume Michal, and A Kiet Tieu
}




\title{
Computational fluid dynamics simulation of carbon dioxide dispersion in a complex environment
}

\author{
Bin Liu, Xiong Liu, Cheng Lu*, Ajit Godbole, Guillaume Michal, Anh Kiet Tieu \\ School of Mechanical, Materials and Mechatronic Engineering, University of Wollongong, NSW 2522, Australia
}

\begin{abstract}
In order to quantitatively evaluate the risk associated with the Carbon Capture and Storage (CCS) technology, a deeper understanding of $\mathrm{CO}_{2}$ dispersion resulting from accidental releases is essential. $\mathrm{CO}_{2}$ is a heavier-than-air gas. Its dispersion patterns may vary according to local conditions. This study focuses on $\mathrm{CO}_{2}$ dispersion over complex terrains. Computational Fluid Dynamics (CFD) models were developed to simulate the $\mathrm{CO}_{2}$ dispersion over two hypothetical topographies: (1) a flat terrain with an axisymmetric hill and (2) a simplified model of an urban area with buildings. The source strength, wind velocity and height of the buildings were varied to investigate their effects on the dispersion profile. The study may offer a viable method for assessment of risks associated with CCS.
\end{abstract}

Keywords: Carbon Capture and Storage (CCS); Consequence analysis; Carbon dioxide $\left(\mathrm{CO}_{2}\right)$ dispersion; Computational fluid dynamics (CFD) modelling

* Corresponding author. Tel.: +61-2-4221-4639; Fax: +61-2-4221-5474.

E-mail address: chenglu@uow.edu.au (C. Lu).

\section{Introduction}

The Carbon Capture and Storage (CCS) technique is widely seen as an effective and economical methodology to control what is perceived to be excessive concentration of Carbon Dioxide $\left(\mathrm{CO}_{2}\right)$ in the earth's atmosphere (Vianello et al., 2012). $\mathrm{CO}_{2}$ is the main contributor to the 'greenhouse effect'. The CCS technique involves capturing waste $\mathrm{CO}_{2}$ from large sources such as fossil fuel-powered electricity generation plants, transporting it to a storage site, and depositing it in underground 
sequestration sites (Liu et al., 2014; Tola and Pettinau, 2014). Commercial-scale transport of $\mathrm{CO}_{2}$ uses tanks, ships, trains and pipelines. Pipelines are preferred when large quantities of $\mathrm{CO}_{2}$ need to be transported over long distances (IPPC, 2005). When using pipelines to transport $\mathrm{CO}_{2}$, safety issues must be considered (Lipponen et al., 2011). $\mathrm{CO}_{2}$ pipeline failures or other releases associated with CCS are usually caused by third party interference, pipeline material corrosion, material defects, operator errors and ground movement (Gale and Davison, 2004). $\mathrm{CO}_{2}$ is colourless and odourless under ambient conditions, and therefore escapes easy detection. It is also an asphyxiant which will lead to rapid loss of consciousness in humans if the exposure level exceeds $10 \%$ (OSHA, 1989). $\mathrm{CO}_{2}$ released from pipelines can disperse downwind, potentially affecting populations and the environment. Therefore, obtaining a deeper understanding of the dispersion of $\mathrm{CO}_{2}$ released from pipelines under different conditions is essential for assessing the safety of the technique.

In recent years, a number of models have been proposed to estimate the atmospheric dispersion of gases resulting from accidental or planned release. These can be classified into three categories: (a) "Gaussian-based" models, (b) "Similarity-profile" models, and (c) Computational fluid dynamics (CFD) models (Koopman et al., 1989). CFD models use more detailed mathematical descriptions of the conservation principles, allowing the simulation of complex physical processes involving heat and mass transport in complicated computational domains. Although time-consuming, CFD models are more appropriate for the modelling of dispersion over complex terrains and under different meteorological conditions. Using CFD for dispersion modelling in all its complexity (terrain topography, presence of obstacles, etc.) is a relatively recent development (Hsieh et al., 2013; Kiša and Jelemenský, 2009; Labovský and Jelemenský, 2010; Liu et al., 2014; Mazzoldi et al., 2008, 2011; Tauseef et al., 2011; Xing et al., 2013). In the past decades, a few researchers have used generalpurpose CFD packages (such as Fluent or CFX) for atmospheric dispersion modelling (Hsieh et al., 2013; Labovský and Jelemenský, 2011; Mazzoldi et al., 2011; Xing et al., 2013), while others have relied on CFD software packages (such as fluidyn-PANACHE) designed specifically for atmospheric dispersion modelling (Hill et al., 2011; Mazzoldi et al., 2008).

Although numerical simulation of the atmospheric dispersion of hazardous gases over flat terrains 
using CFD is a relatively recent development, there have been some reports in the literature. Labovsky and Jelemensky (2011) used the CFD software Fluent to model the dispersion of ammonia in the 'Fladis' field experiments. They found that it was important to model the turbulence level appropriately. Mazzoldi et al. (2008) evaluated the suitability of the dispersion simulation tool fluidyn-PANACHE using data from the Prairie Grass and Kit Fox field experiments for validation. Xing et al. (2013) carried out a scaled experiment on a $\mathrm{CO}_{2}$ release for the purpose of measuring the downwind concentration levels. In their experiment, the $\mathrm{CO}_{2}$ was released vertically from a circular source at ground level at different flow rates. In addition, CFD simulations were carried out using different turbulence models. They concluded that the results of simulations using the $k-\varepsilon$ and the shear stress transport (SST) $k-\omega$ turbulence models were in acceptable agreement with the experimental data. Mazzoldi et al. (2011) compared two atmospheric dispersion models, the Gaussian model and a CFD model, taking representative input parameters for high-pressure $\mathrm{CO}_{2}$ releases. Results showed a lowering of the risk involved in the transportation of $\mathrm{CO}_{2}$ by up to one order of magnitude, when modelling the same releases with a CFD tool, compared to the more widespread Gaussian models. Mocellin et al. (2015) simulated the accident release of $\mathrm{CO}_{2}$ from CCS pipelines and the consequences related to a sublimating dry ice bank. Results showed that serious risks were associated to the sublimating dry ice bank near the release point and that the hazard level increases with a decreasing mean wind speed and at higher ambient temperature. Liu et al. (2014) used CFD techniques to simulate the atmospheric dispersion of $\mathrm{CO}_{2}$ released from a high-pressure pipeline. Two cases in the $\mathrm{CO}_{2}$ dispersion experiments carried out by DNV BP (Trial DF1) were simulated for validation (Witlox, 2006), and DNV Phast was employed for comparative studies. The above studies suggested that realistic representations of the 'Atmospheric Boundary Layer' and turbulence levels are crucial in CFD modelling.

In recent years, the modelling of hazardous gas dispersion over complex terrains has attracted increasing attention. McBride et al. (2001) simulated the dispersion of chlorine and found that complex terrain and buildings affected not only the downwind hazard range, but also the width of the dispersion cloud and its direction of travel. Chow et al. (2009) proposed a model to simulate the 
atmospheric dispersion of $\mathrm{CO}_{2}$ resulting from a leakage. The results demonstrated even small topographical features had a notable effect on the dispersion of the heavy gas. Scargiali et al. (2011) simulated the formation of toxic clouds of a heavy gas in an urban area using the CFD package ANSYS CFX. The simulation strategy involved a steady-state simulation to establish the pre-release wind velocity field, followed by a transient after-release simulation. The computational domain was modelled as a simple network of straight roads with regularly distributed blocks mimicking buildings. Results showed that the presence of buildings lowered the maximum concentration and enhanced the lateral spread of the cloud. Dispersion dynamics was also found to be strongly dependent on the quantity of the heavy gas released. Tauseef et al. (2011) applied CFD techniques in an assessment of heavy gas dispersion in the presence of a cubical obstacle downstream of the source. The performance of different turbulence models was investigated. They found that the realizable $k$ - $\varepsilon$ model is slightly superior. Hsieh et al. (2013) studied the dispersion of $\mathrm{CO}_{2}$ from a CCS-related infrastructure in a complex hypothetical topography. The simulated concentration levels were found to be reasonable. Overall, the presence of an obstacle and/or complex terrain has a significant influence on heavy gas dispersion. However, generally speaking, the research associated with $\mathrm{CO}_{2}$ dispersion over complex terrains is in its early stages. For quantification of the risks associated with $\mathrm{CO}_{2}$ dispersion, an appropriate dispersion model especially over complex terrains is essential.

This study focuses on an investigation of $\mathrm{CO}_{2}$ dispersion over complex terrains using CFD techniques. Two hypothetical topographies, a flat terrain with an axisymmetric hill, and a model urban area with buildings, were chosen to investigate the topographical effects on the dispersion. The influences of source strength and wind velocity on the dispersion were also taken into account. This study may contribute towards offering a reliable methodology for risk assessment related to CCS.

\section{Numerical methods and experimental validation}

\subsection{Basic equations}

The CFD software ANSYS-Fluent provides a method to solve three-dimensional conservation equations for the mean quantities in a turbulent flow field. The conservation equations of mass, 
momentum, energy and species concentration are solved. The standard $k-\varepsilon$ turbulence model is chosen in this simulation because it has been widely validated in dispersion simulations (Kiša and Jelemenský, 2009; Scargiali et al., 2011; Sini et al., 1996; Xing et al., 2013). The turbulent kinetic energy $k$ and the turbulent kinetic energy dissipation rate $\varepsilon$ are two key parameters in these equations.

The basic equations are (Launder, 1972):

Continuity equation:

$$
\frac{\partial \rho}{\partial t}+\frac{\partial}{\partial x_{i}}\left(\rho u_{i}\right)=0
$$

where $\rho$ is the density, $t$ the time, and $u_{\mathrm{i}}$ the velocity component along the $x_{\mathrm{i}}$ direction.

Momentum equation (Reynolds-Averaged Navier-Stokes equations):

$$
\frac{\partial}{\partial t}\left(\rho u_{i}\right)+\frac{\partial}{\partial x_{i}}\left(\rho u_{i} u_{j}\right)=-\frac{\partial p}{\partial x_{i}}+\frac{\partial}{\partial x_{j}}\left(\mu \frac{\partial u_{i}}{\partial x_{j}}-\rho \overline{u_{i}^{\prime} u_{j}^{\prime}}\right)
$$

where $p$ is the pressure and $\mu$ is the dynamic viscosity of the fluid.

Energy equation:

$$
\frac{\partial}{\partial t}(\rho E)+\nabla \cdot[\vec{v}(\rho E+p)]=\nabla \cdot\left(k_{e f f} \nabla T-\sum_{j} h_{j} \vec{J}_{j}+\bar{\tau}_{e f f} \cdot \vec{v}\right)+S_{h}
$$

where $E$ is the total specific energy, $k_{\text {eff }}$ the effective thermal conductivity, $h_{j}$ the enthalpy of species $j$,

$\vec{J}_{j}$ the diffusion flux of species $j$, and $S_{h}$ the source term.

The parameters $k$ and $\varepsilon$ are defined as:

$$
\begin{gathered}
k=\frac{\overline{u^{\prime 2}}+\overline{v^{\prime 2}}+\overline{w^{\prime 2}}}{2} \\
\varepsilon=\frac{\mu}{\rho} \overline{\left(\frac{\partial u_{l}^{\prime}}{\partial x_{k}}\right)\left(\frac{\partial u_{l}^{\prime}}{\partial x_{k}}\right)}
\end{gathered}
$$

The turbulent viscosity $\mu_{t}$ is a function of $k$ and $\varepsilon$. 


$$
\mu_{t}=\frac{C_{u} \rho k^{2}}{\varepsilon}
$$

$k$ and $\varepsilon$ are both unknown variables which can be calculated from the differential 'conservation' equations for $k$ and $\varepsilon$ :

$$
\begin{aligned}
& \frac{\partial}{\partial t}(\rho \kappa)+\frac{\partial}{\partial x_{j}}\left(\rho \mu_{j}\right)=\frac{\partial}{\partial x_{j}}\left[\left(\mu+\frac{\mu_{t}}{\sigma_{k}}\right) \frac{\partial k}{\partial x_{j}}\right]+G_{k}-\rho \varepsilon \\
& \frac{\partial}{\partial t}(\rho \varepsilon)+\frac{\partial}{\partial x_{i}}\left(\rho u_{j}\right)=\frac{\partial}{\partial x_{j}}\left[\left(\mu+\frac{\mu_{t}}{\sigma_{\varepsilon}}\right) \frac{\partial \varepsilon}{\partial x_{j}}\right]+G_{1 \varepsilon} \frac{\varepsilon}{\kappa} G_{k}-C_{2 \varepsilon} \rho \frac{\varepsilon^{2}}{\kappa}
\end{aligned}
$$

The recommended model constants are: $C_{1 \varepsilon}=1.44, C_{2 \varepsilon}=1.92, C_{\mu}=0.09, \sigma_{\mathrm{\kappa}}=1.0, \sigma_{\varepsilon}=1.3$ (Launder, 1972) .

As in this study, as the $\mathrm{CO}_{2}$ is released at ambient pressure and with relatively low velocity, the flow is considered incompressible. Therefore, both $\mathrm{CO}_{2}$ and air are defined as incompressible ideal gases in the CFD code.

The conservation of the local mass fraction of each species $Y_{i}$ is expressed as:

$$
\begin{aligned}
& \frac{\partial}{\partial t}\left(\rho Y_{i}\right)+\nabla \cdot\left(\rho \bar{v} Y_{i}\right)=-\nabla \cdot \bar{J}_{i} \\
& \overrightarrow{J_{i}}=-\left(\rho D_{i, m}+\frac{\mu_{t}}{S c_{t}}\right) \nabla Y_{i}-D_{T, i} \frac{\nabla T}{T}
\end{aligned}
$$

where $Y_{\mathrm{i}}$ is obtained through the solution of a convection-diffusion equation for the $i^{\text {th }}$ species. In equation (9), $\vec{J}_{i}$ is the diffusion flux of species $i, \mu_{\mathrm{t}}$ is the turbulent viscosity and $D_{\mathrm{t}}$ is the turbulent diffusivity.

The turbulent Schmidt number is calculated using:

$$
S c_{t}=\frac{\mu_{t}}{\rho D_{t}}
$$

The default value of $S c_{t}$ is 0.7 (Launder, 1972). 


\subsection{Experimental validation}

A $\mathrm{CO}_{2}$ dispersion experiment carried out by Xing et al. from the Beijing Institute of Technology, China (Xing et al., 2013), was simulated, and the simulation results were compared with measurements. This experiment was carried out in a partially enclosed box-shaped space (length $15 \mathrm{~m}$, width $6.4 \mathrm{~m}$, height $5.2 \mathrm{~m}$ ) with the 'front' and the 'rear' open to the atmosphere (Fig. 1). The distance between the farthest monitor point and the open front was $11 \mathrm{~m}$. A circular $\mathrm{CO}_{2}$ source with a diameter of $2 \mathrm{~cm}$ was located at ground level, $1 \mathrm{~m}$ from the front, and midway between the side walls. The $\mathrm{CO}_{2}$ volume flow rate ranged from 0 to $20 \mathrm{~m}^{3} \mathrm{~h}^{-1}$. It could be accurately measured and controlled during the experiment. The wind blew from the 'Front' to the 'Rear'. The wind speed and direction were measured by a sonic anemometer at $2 \mathrm{~m}$ height. Two thermometers were deployed: one was near the $\mathrm{CO}_{2}$ source to measure its temperature; the other was in the middle. Along the central line there arranged a total of ten sensors which were used to measure the $\mathrm{CO}_{2}$ concentration. The distances between the source and each sensor were $0.5,1.5,2,2.5,3,4,6.5,6,8$, and $10 \mathrm{~m}$, respectively. To validate the model, we selected two cases with volume flow rates $10 \mathrm{~m}^{3} \mathrm{~h}^{-1}$ and $12 \mathrm{~m}^{3} \mathrm{~h}^{-1}$, which were converted into release speeds of approximately $8.8 \mathrm{~m} \mathrm{~s}^{-1}$ and $10.6 \mathrm{~m} \mathrm{~s}^{-1}$ at the source respectively.

The velocity profile of the wind inlet was specified by a power law correlation to simulate an atmospheric boundary layer. This has been successfully used by a number of researchers (Liu et al., 2014; Sklavounos and Rigas, 2004; Xing et al., 2013). The correlation is:

$$
u=u_{r}\left(\frac{z}{z_{r}}\right)^{\alpha}
$$

where $u_{r}$ is the reference wind velocity measured at the reference height $z_{r}$, and $\alpha$ the wind shear exponent which is defined by the atmospheric stability class and the ground surface roughness. In accordance with the experimental arrangement, parameters for the inlet wind profile were set as: $\alpha=$ $0.3, u_{r}=0.6 \mathrm{~m} \mathrm{~s}^{-1}$ and $z_{r}=2 \mathrm{~m}$. Fig. 1 gives the schematic of the computational domain. The boundary conditions are summarised in Table 1.

To ensure a grid-independent simulation, a grid sensitivity analysis was performed by using several 
grid sizes. It was found that when increasing grid size from 285207 cells to 582561 cells, the change in the simulation results of timing-varying concentration of $\mathrm{CO}_{2}$ is very limited, as shown in Fig. 2 . Thus, the grid with 285207 cells was used for the subsequent simulations.

Fig. 3 compares the calculated downwind centreline concentration of $\mathrm{CO}_{2}$ at $200 \mathrm{~s}$ after its release with the experimental data. It can be observed that the CFD model slightly underestimated the $\mathrm{CO}_{2}$ concentration in the 'near-field' region close to the source. Farther from the source, the CFD models performed much better. The simulated concentration along the centreline agrees well with the experimental data for all release rates $\left(10 \mathrm{~m}^{3} \mathrm{~h}^{-1}, 12 \mathrm{~m}^{3} \mathrm{~h}^{-1}, 15 \mathrm{~m}^{3} \mathrm{~h}^{-1}, 18 \mathrm{~m}^{3} \mathrm{~h}^{-1}\right)$, as shown in Fig. 3 . Clearly, the $\mathrm{CO}_{2}$ concentration in the near-field region was over-predicted by Xing et al. In the farfield region, the concentration predicted by Xing et al. also showed worse agreement with the measurements. The larger discrepancies between the measurements and the results predicted by Xing et al. may be mainly due to the smaller computational domain they used. The physical domain for the experiment was measured $15 \mathrm{~m}$ (length) $\times 6.4 \mathrm{~m}$ (breadth) $\times 5.2 \mathrm{~m}$ (height), with top, left and right sides enclosed by walls. In their study, Xing et al. employed a computational domain measuring $11 \mathrm{~m}$ $\times 3 \mathrm{~m} \times 3 \mathrm{~m}$. The top, left and right sides were defined as pressure outlet boundaries. This will introduce greater impact from the boundary conditions.

Fig. 4 shows the simulated time history of $\mathrm{CO}_{2}$ concentration at ground level $3 \mathrm{~m}$ downstream from the source. The results predicted by Xing et al. (2013) are also presented in the figure. In both cases, the CFD models predicted a concentration peak around $15 \mathrm{~s}$, after which the $\mathrm{CO}_{2}$ concentrations gradually reduce. This trend was also predicted by Xing et al. However this does not agree with the measured data, in which the concentration gradually increases until it reaches a relatively stable plateau. This may be due to the measurement technique, in which it appears that the initial quick variation in the concentration was not recorded. After the initial variation, the CFD models in this study predicted a stable plateau. This agrees with the measurements. For case (a) with $10 \mathrm{~m}^{3} \mathrm{~h}^{-1}$ release rate, the predicted stable concentration is close to the measured data, showing better agreement than the results predicted by Xing et al. For case (b) with $12 \mathrm{~m}^{3} \mathrm{~h}^{-1}$ release rate, the CFD model over-predicted the stable concentration (Xing et al., 2013; Gavelli et al., 2008). 
Although there are some discrepancies between the CFD predictions and experimental measurements, the CFD models showed acceptable performance, especially in the far-field region. The predicted concentration along the centreline has reasonably good agreement with the experimental data. The time-varying concentration was successfully predicted when the dispersion approaches the steady state. This indicates that the proposed numerical methods can be used to simulate the dispersion of $\mathrm{CO}_{2}$, particularly in the far-field region.

\section{CFD Models for dispersion over complex terrains}

\subsection{Modelled terrain types}

$\mathrm{CO}_{2}$ dispersion over two types of terrain was investigated. The first (Terrain A) is a flat terrain with a hill located downwind of the source, while the second (Terrain B) mimics an urban area using boxshaped blocks to represent buildings.

For Terrain A, the paraboloid shape of the three-dimensional hill was defined as:

$$
Z_{s}(x, y)=h \cos ^{2}\left[\frac{\pi \sqrt{\left(x-x_{0}\right)^{2}+\left(y-y_{0}\right)^{2}}}{2 L}\right]
$$

where $h$ is the maximum height of the hill, $\left(x_{0}, y_{0}\right)$ the position of the hill centre at ground level and $L$ the base radius of the hill. In this study, $h$ and $L$ are defined as $40 \mathrm{~m}$ and $50 \mathrm{~m}$ respectively. The horizontal distance between $\mathrm{CO}_{2}$ source and $\left(x_{0}, y_{0}\right)$ is $85 \mathrm{~m}$. A cross section of the hill in the vertical plane of symmetry is shown in Fig. 5.

The urban area for Terrain B is simply modelled using regular blocks to mimic buildings and streets. The blocks are arranged in 4 rows and 4 columns, as shown in Fig. 6. The length and width of each building are $10 \mathrm{~m}$ and $8 \mathrm{~m}$ respectively. The height of all buildings is varied in the simulations in order to assess its influence on the dispersion. The distance between the centre of the $\mathrm{CO}_{2}$ source and the first row of buildings is $20 \mathrm{~m}$. The space between two buildings in the longitudinal direction is 10 $\mathrm{m}$, while that in the lateral direction is $8 \mathrm{~m}$. 


\subsection{Computational domain and Boundary conditions}

Fig. 7 shows the box-shaped computational domain for Terrain A. The overall dimensions of the computational domain are $500 \mathrm{~m}$ (length) $\times 500 \mathrm{~m}$ (breadth) $\times 200 \mathrm{~m}$ (height). The $\mathrm{X}-\mathrm{Y}$ plane is placed on the ground, with the $\mathrm{X}$-axis oriented along the wind. $\mathrm{CO}_{2}$ is released vertically from a circular area source with a diameter of $1.5 \mathrm{~m}$ at ground level. The computational domain is discretised in the form of hexahedral cells. The mesh is refined near the $\mathrm{CO}_{2}$ source and ground. The total number of cells in the grid is 6306024 which enabled the grid-independent simulation (see Fig. 8 for part of the computational mesh of terrain A near the source and hill).

Seven boundary conditions are defined in this model: (1) wind inlet, (2) $\mathrm{CO}_{2}$ source, (3) ground, (4) side 1, (5) side 2, (6) top, and (7) outlet of the computation domain. The $\mathrm{CO}_{2}$ source is specified by a velocity inlet. The top, side 1 and side 2 boundaries are defined as impermeable symmetry boundaries with zero normal velocity and zero gradients of all variables. The outlet is set as a pressure boundary with ambient pressure and temperature. The ground is defined as a no-slip, isothermal wall with temperature equal to the ambient temperature. The velocity profile at the wind inlet is specified by a power law correlation as shown in Eq. (12).

The values of $\alpha=0.1343, z_{r}=10 \mathrm{~m}$ in Eq. (12) are chosen in these simulations. Two reference wind velocities, $u_{r}=2 \mathrm{~m} \mathrm{~s}^{-1}$ and $6 \mathrm{~m} \mathrm{~s}^{-1}$, are chosen to study the influence of weather conditions on the dispersion.

The boundary conditions for the CFD model simulating Terrain B are similar to those for Terrain A. For this case, the dimensions of the computational domain are $500 \mathrm{~m}$ (length) $\times 500 \mathrm{~m}$ (breadth) $\times$ $200 \mathrm{~m}$ (height). The diameter of the $\mathrm{CO}_{2}$ source area is $0.5 \mathrm{~m}$. The computational domain is also discretised in the form of hexahedral cells, with refinement near the $\mathrm{CO}_{2}$ source, building surfaces and the ground. The number of cells in the computational domain ranges from $6.3 \times 10^{6}$ to $8.5 \times 10^{6}$ for different building heights. A detail of the mesh around a typical building is shown in Fig. 9 . 


\subsection{Initial condition}

Initially, a steady-state simulation was carried out to establish the wind flow field in the computational domain. This provides the initial condition for the subsequent transient simulation of $\mathrm{CO}_{2}$ dispersion. Fig. 10 shows the simulated streamline pattern around the hill in the symmetry plane. It is found that the streamline becomes sparse in the lee side of the hill when the wind velocity is low and the recirculation in the lee side of the hill when the wind velocity is relatively high, which corresponds a relatively high Reynolds number. This will provide an appropriate initial flow field for the subsequent dispersion simulation.

\section{Results and discussion}

For a vertical $\mathrm{CO}_{2}$ release at ground level, the source flow shows strong interaction with the wind flow in the near field. Fig 11 shows the simulated streamline pattern in the "symmetry plane" of the computation domain near the $\mathrm{CO}_{2}$ source for release velocities of $10 \mathrm{~m} \mathrm{~s}^{-1}$ (Fig. 10a) and $20 \mathrm{~m} \mathrm{~s}^{-1}$ (Fig. 10b). The $\mathrm{CO}_{2}$ source centre is at $x=15 \mathrm{~m}$. The streamline patterns in Fig. 11 reveal that the released gas acts as a strong, single 'obstacle' to the wind flow forming a recirculation region slightly downstream of the $\mathrm{CO}_{2}$ source. This phenomenon may influence the subsequent dispersion.

\subsection{Simulation results - Terrain A}

In the study of $\mathrm{CO}_{2}$ dispersion over Terrain $\mathrm{A}, 8$ cases were simulated, considering four source velocities and two wind velocities (see Table 2).

In the simulation of dispersion over Terrain A, the convergence criterion for energy was defined as the residual becoming equal or less than $10^{-6}$, while for other variables such as velocity, $k, \varepsilon$ and $\mathrm{CO}_{2}$ fraction, the convergence criterion was set as the residual $<=10^{-4}$. Fig. 12 shows the convergence history during the first 20 time steps of the transient simulation for Case 1. For the first several time steps, the solver could lead to successful convergence within 40 iterations. After about 10 time steps, the required iteration number for convergence is reduced to 10 .

The National Institute for Occupational Safety and Health (NIOSH) (Hsieh et al., 2013) suggests that 
an exposure to $\mathrm{CO}_{2}$ concentration levels of $4 \%$ is immediately dangerous to life or health. The ShortTerm Exposure Limit (STEL) of $1.5 \%$ is used as a guide for maximum safe exposure. This is the concentration below which no ill effect will be observed on people after a 15-minute exposure (Mazzoldi, 2009; HSE, 2007). Figs. 13, 14 and 16 show the simulation results for $v_{\text {wind }}=2 \mathrm{~m} \mathrm{~s}^{-1}$. Fig. 13 shows the contours for $\mathrm{CO}_{2}$ concentration levels $4 \%$ (red contour) and $1.5 \%$ (green contour) at ground level, $250 \mathrm{~s}$ after the release when the dispersion is expected to approach a steady state. It is clear that in front of the hill (windward) there exists a high $\mathrm{CO}_{2}$ concentration area due to the obstruction presented by the hill. But the high concentration area seems to be smaller when the source velocity is increased high enough that the $\mathrm{CO}_{2}$ cloud can rise over the hilltop. Given that $\mathrm{CO}_{2}$ is a heavier-than-air gas, it has a natural tendency to sink during dispersion. For a vertical release with low initial velocity, it is hard for $\mathrm{CO}_{2}$ to surmount the hill. Thus a large amount of the heavy gas will accumulate on the windward side of the hill.

It is interesting to notice that although the hilltop is the highest point in the domain, for a vertical release, high $\mathrm{CO}_{2}$ concentration can still occur at the hilltop if the source velocity is high enough (Fig. 13). Therefore, it is possible that higher concentration can occur at high altitudes, depending on the release direction, source strength, and the topography, even for a relatively heavy gas.

The dispersion following a vertical $\mathrm{CO}_{2}$ release can be divided into four stages. In the first stage, the initial source velocity dominates the near field dispersion. The effect of air entrainment on the $\mathrm{CO}_{2}$ dispersion is limited. In the second stage, the $\mathrm{CO}_{2}$ plume is gradually diluted by the ambient air, leading to a reduction in the density of the dispersing cloud. Simultaneously, gravity becomes increasingly dominant. In the third stage, when the gas is sufficiently diluted by the ambient air, the gravitational and buoyancy effects tend to be balanced. The $\mathrm{CO}_{2}$ cloud descends slightly even as it becomes bigger. In the fourth and final stage, when the $\mathrm{CO}_{2}$ cloud is further diluted, the process approaches a condition which represents a neutrally buoyant cloud. Then the gas becomes a passive contaminant. In the third stage, if the $\mathrm{CO}_{2}$ cloud just reaches the hilltop, the concentration on the hilltop surface will be unacceptably high. 
Fig. 14 shows the $\mathrm{CO}_{2}$ concentration contours on the ground for case 1 and case 4 at different times. For case 1, when the $\mathrm{CO}_{2}$ cloud encounters the hill, a part of the heavy gas goes around the obstacle, and the remainder accumulates on the windward face of the hill. For case 4, when the flow of $\mathrm{CO}_{2}$ encounters the obstacle, most of the heavy gas reaches the hilltop. A small fraction goes around the hill, while the remainder accumulates on the windward side of the hill. This makes the high concentration area around the hill to be relatively smaller. This indicates that the terrain type and release velocity both have a combined influence on the dispersion of the heavy gas.

During the simulations, the concentration history was monitored at 4 points. As shown in Fig. 15, point $\mathrm{A}$ is located at the hill top, while point $\mathrm{C}$ is placed at the right side of the hill. Point $\mathrm{B}$ and point $\mathrm{D}$ are located in the windward and leeward of the hill respectively. Fig. 16 gives the $\mathrm{CO}_{2}$ concentration time histories at these points for various release velocities.

As shown in Fig. 16a, at point A (hill-top), the concentration rises with increasing source velocity. The $\mathrm{CO}_{2}$ concentration is extremely low when $v_{\text {source }}=10 \mathrm{~m} \mathrm{~s}^{-1}$, and is much higher for $v_{\text {source }}=40 \mathrm{~m} \mathrm{~s}^{-}$ ${ }^{1}$ than for the other three release velocities. One reason is that the $\mathrm{CO}_{2}$ mass flow rate is high when $v_{\text {source }}=40 \mathrm{~m} \mathrm{~s}^{-1}$. The other reason is that when the vertical source velocity is higher, the $\mathrm{CO}_{2}$ can surmount higher barriers or reach higher altitudes. When the source velocity is relatively low, such as $v_{\text {source }}=10 \mathrm{~m} \mathrm{~s}^{-1}$, the $\mathrm{CO}_{2}$ cloud struggles to reach the hill top. From Fig. 13 we find that $\mathrm{CO}_{2}$ with $4 \%$ concentration can reach the hill-top only when $v_{\text {source }}=40 \mathrm{~m} \mathrm{~s}^{-1}$. When $v_{\text {source }}=10 \mathrm{~m} \mathrm{~s}^{-1}$, even $\mathrm{CO}_{2}$ with $1.5 \%$ concentration is not able to reach the hilltop.

As shown in Fig. 16b, in case 1, 2 and 3, the $\mathrm{CO}_{2}$ concentrations at point $\mathrm{B}$ (windward face of the hill) are higher than those at the other three points. Especially when $v_{\text {source }}=10 \mathrm{~m} \mathrm{~s}^{-1}$, the concentration nearly reaches $10 \%$. This indicates that the windward face of the hill is the most likely to experience excessively high $\mathrm{CO}_{2}$ concentrations when $\mathrm{CO}_{2}$ cannot summit the hill. Notice that when $v_{\text {source }}=40$ $\mathrm{m} \mathrm{s}^{-1}$, the concentration is relatively lower than other leak velocity. The reason is that most of $\mathrm{CO}_{2}$ summit the hill.

As shown in Fig. 16c, because of the blockage of the hill, the $\mathrm{CO}_{2}$ tends to disperse around the hill. 
But if the initial momentum of the source is high enough, the gas can also go over the hilltop, resulting in lower concentration on the lateral sides of the hill. This is reflected in Fig. 16c, while at point $\mathrm{C}$ ( side of the hill), the $\mathrm{CO}_{2}$ concentration for $v_{\text {source }}=30 \mathrm{~m} \mathrm{~s}^{-1}$ is higher than that for $v_{\text {source }}=40$ $\mathrm{m} \mathrm{s}^{-1}$.

As shown in Fig. 16d, the $\mathrm{CO}_{2}$ concentrations at point D (leeward side of the hill) in all of the four cases are lower than those at the other three points. This indicates that the leeward of the hill is the safest. Compared to other three cases, the $\mathrm{CO}_{2}$ concentration for $v_{\text {source }}=10 \mathrm{~m} \mathrm{~s}^{-1}$ is the lowest. This is due to the fact that the $\mathrm{CO}_{2}$ finds it harder to go across the hill with a lower initial momentum, as most of the $\mathrm{CO}_{2}$ on the leeward side is made up of the part that has gone over the hilltop.

Fig. 17 shows the iso-surface of $1.5 \% \mathrm{CO}_{2}$ concentration under different conditions. Clearly, the lateral spread of the $\mathrm{CO}_{2}$ cloud is smaller when the wind is stronger. This is because the stronger wind can result in quicker downstream dispersion. In addition, when $v_{\text {source }}=30 \mathrm{~m} \mathrm{~s}^{-1}$, the cloud can reach the hilltop when $v_{\text {wind }}=6 \mathrm{~m} \mathrm{~s}^{-1}$. It should be noted that when $v_{\text {source }}=30 \mathrm{~m} \mathrm{~s}^{-1}$, the downwind cloud spread for $v_{\text {wind }}=2 \mathrm{~m} \mathrm{~s}^{-1}$ is greater than that for $v_{\text {wind }}=6 \mathrm{~m} \mathrm{~s}^{-1}$. On the contrary, when $v_{\text {source }}=10 \mathrm{~m} \mathrm{~s}^{-1}$, the downwind cloud spread for $v_{\text {wind }}=2 \mathrm{~m} \mathrm{~s}^{-1}$ is shorter than that for $v_{\text {wind }}=6 \mathrm{~m} \mathrm{~s}^{-1}$. This is because of the combined effects of the release velocity and wind velocity in case 7, which make the cloud go over the hill top and change the main dispersion direction to downwind.

\section{2 $\mathrm{CO}_{2}$ dispersion in an urban landscape}

In the study of $\mathrm{CO}_{2}$ dispersion over Terrain $\mathrm{B}$, three building-heights, $4.2 \mathrm{~m}, 7.2 \mathrm{~m}$ and $10.2 \mathrm{~m}$, were considered. The release velocity is set as $10 \mathrm{~m} \mathrm{~s}^{-1}$. Two reference wind velocities $u_{\mathrm{r}}=2 \mathrm{~m} \mathrm{~s}^{-1}$ and $u_{\mathrm{r}}=$ $6 \mathrm{~m} \mathrm{~s}^{-1}$ were used. Similar to the cases for Terrain A, the same convergence criteria were defined for the flow variables. Fig. 18 shows the convergence history of the first 20 time steps of the transient simulation for the case with building height of $4.2 \mathrm{~m}$ and wind velocity of $2 \mathrm{~m} \mathrm{~s}^{-1}$. It is observed that stable convergence was achieved for each time step.

Fig. 19 shows the iso-surface for $1.5 \% \mathrm{CO}_{2}$ concentration for the domain with different building heights when $u_{\mathrm{r}}=2 \mathrm{~m} \mathrm{~s}^{-1}, 300 \mathrm{~s}$ after the release. The development of the $\mathrm{CO}_{2}$ plume mainly follows 
the wind direction and fills the central longitudinal street. Due to the blockage of the buildings, it also disperses laterally and fills a part of the side streets. For low building height $(4.2 \mathrm{~m})$, the building roof or top floor can experience relatively high $\mathrm{CO}_{2}$ concentrations. It is clear that in the first aisle, the impact area of $1.5 \%$ concentration decreases with the increase of the building height. This indicates that taller buildings have greater impact on the transversal dispersion. It should be noted that though the $\mathrm{CO}_{2}$ concentration is less than $1.5 \%$ at position $\mathrm{P}$, which is near the wall of buildings in Column 2 , the concentration is greater than $1.5 \%$ near the wall of building $\mathrm{A}$, which is even farther from the source. The concentration rises primarily because the presence of building A prevents the transversal dispersion and then the $\mathrm{CO}_{2}$ piles up near the wall of buildings. It demonstrates that the concentration may be relatively high even at locations relatively far from the source, depending upon the locations and sizes of the buildings.

Fig. 19 shows that the region of $1.5 \%$ concentration in the first and second rows of the building and the first transverse street is the widest for a building height $4.2 \mathrm{~m}$. This is due to the fact that the $\mathrm{CO}_{2}$ can arrive at the walls of the second column at $1.5 \%$ concentration, as the heavy gas cannot surmount the roof if the building height is $7.2 \mathrm{~m}$ or $10.2 \mathrm{~m}$. Therefore most of the $\mathrm{CO}_{2}$ is trapped in the central longitude street downwind of the source, making the $\mathrm{CO}_{2}$ concentration higher in that region and the lateral spread smaller. This indicates that the building height has a complicated effect on the dispersion. In the second and third transverse streets, the cloud stays near the walls of the buildings. These results demonstrate that the buildings impede the dispersion of $\mathrm{CO}_{2}$, and most of the $\mathrm{CO}_{2}$ disperses along the streets and part of it can go over the roof. The higher the building is, the more the heavy $\mathrm{CO}_{2}$ disperses along the streets.

The presence of buildings not only prevents the dispersion to some extent, but also presents an obstacle to the wind. The $\mathrm{CO}_{2}$ tends to be trapped in the streets for all three building heights. Fig. 20 shows the recirculating streamline patterns between the buildings in the first row of buildings (building height: $\mathrm{H}=4.2 \mathrm{~m}$ ). The recirculation leads to the trapping and accumulation of $\mathrm{CO}_{2}$ in the streets, especially the anticlockwise recirculation makes a high concentration near the wall. Fig. 21 shows the $\mathrm{CO}_{2}$ concentration contours in the middle section of the first column buildings. Higher 
concentrations are observed near the buildings, especially the windward wall experiencing the highest concentration. This indicates that in an urban area, the region close to the windward wall is the most hazardous.

Fig. 22 shows the downwind $\mathrm{CO}_{2}$ concentration along the centreline, $300 \mathrm{~s}$ after the release, for three building heights. The curves show that before the $\mathrm{CO}_{2}$ meets the building, the concentration increases with distance from the source and reaches a maximum just at the walls of the first row of the buildings. This is due to the impact of the first row of buildings. Subsequently, the concentration falls sharply until the distance from the source is about $50 \mathrm{~m}$. Thereafter the concentration rises slightly from the third transverse street. After all the buildings have been traversed, the concentration decreases slightly again. It is also observed that the building height affects the maximum downwind $\mathrm{CO}_{2}$ concentration. For building height of $4.2 \mathrm{~m}$, the maximum $\mathrm{CO}_{2}$ concentration is the lowest. This is because in this case, $\mathrm{CO}_{2}$ cloud is easier to go over the building roof and less $\mathrm{CO}_{2}$ accumulate in front of the first row. When the building is high enough preventing the $\mathrm{CO}_{2}$ cloud from going across the building roof, increasing the building height has little effect on the maximum concentration. Fig. 23 exhibits the relationship between the downwind distance from the $\mathrm{CO}_{2}$ source and the concentration of $\mathrm{CO}_{2}$ at the central of the ground for different wind conditions $300 \mathrm{~s}$ after the release $(\mathrm{H}=7.2 \mathrm{~m})$. The concentration is higher when $v_{\text {wind }}=2 \mathrm{~m} \mathrm{~s}^{-1}$.

Fig. 24 shows the influence of wind speed on the dispersion. It is clear that the spread of the $\mathrm{CO}_{2}$ cloud decreases significantly - both in lateral direction and longitudinal direction, for higher wind speeds. This is similar to the simulation results of the dispersion over Terrain A, which proves that stronger wind helps the dispersion of $\mathrm{CO}_{2}$.

\section{Conclusions}

This study presents CFD models for $\mathrm{CO}_{2}$ dispersion over complex terrains. The CFD simulations were validated using experimental measurements. Two terrain types were employed to investigate the terrain effects on the dispersion behaviour. The CFD models of experiments performed by Xing et al. (2013) showed good agreement between the simulation results and the measurements of $\mathrm{CO}_{2}$ 
concentration along the downwind centreline when the dispersion reaches a quasi-steady state. The CFD models also successfully predicted the stable concentration plateau after the initial variation.

Results of the dispersion over a flat terrain with a hill indicate that the topography affects the dispersion of $\mathrm{CO}_{2}$ significantly. The presence of hills downwind of the source may significantly shrink the spread of the $\mathrm{CO}_{2}$ cloud, especially when the wind velocity is high. The downwind spread of the $\mathrm{CO}_{2}$ cloud is usually reduced by the presence of the hill and the windward side of the hill experiences higher $\mathrm{CO}_{2}$ concentration. A part of the heavy gas goes around the hill, but for higher release velocity, less $\mathrm{CO}_{2}$ spreads laterally. This makes the high concentration area around the hill to be relatively smaller.

The terrain type and source strength have a combined effect on the dispersion of $\mathrm{CO}_{2}$. For vertical releases, high $\mathrm{CO}_{2}$ concentration can occur at the hilltop if the source velocity is high enough, because the source strength and wind velocity can help the cloud spread to higher altitudes. The leeward of the hill is the safest due to the fact that the $\mathrm{CO}_{2}$ finds it harder to go across the hill, as most of the $\mathrm{CO}_{2}$ on the leeward side is made up of the part that has gone over the hilltop.

In an urban area, the $\mathrm{CO}_{2}$ cloud is usually trapped in the streets between buildings. In the streets, it is more dangerous near the wall, especially near the wind ward wall. The coverage of hazardous area increases with the decrease of building heights, as higher buildings lead to less lateral spread of the $\mathrm{CO}_{2}$ cloud. Higher buildings may lead to higher ground-level maximum $\mathrm{CO}_{2}$ concentration. But when the building is high enough preventing the $\mathrm{CO}_{2}$ cloud from going over the building roof, increasing the building height has little effect on the maximum $\mathrm{CO}_{2}$ concentration.

Strong wind contributes to the dispersion. This was shown in the $\mathrm{CO}_{2}$ dispersion over both two terrain types. Higher wind velocity leads to quicker dispersion, resulting in a smaller impact area.

\section{Acknowledgements}

This work is being carried out under the aegis of the Energy Pipelines Cooperative Research Centre (EPCRC), supported through the Australian Government's Cooperative Research Centre Program, 
and funded by the Department of Resources, Energy and Tourism (DRET). Cash and in-kind support from the Australian Pipelines Industries Association Research and Standards Committee (APIA RSC) is gratefully acknowledged. Scholarship from China Scholarship Council (CSC) and the University of Wollongong for the first author is highly appreciated.

\section{References}

Chow, F.K., Granvold, P.W., Oldenburg, C.M., 2009. Modeling the effects of topography and wind on atmospheric dispersion of $\mathrm{CO} 2$ surface leakage at geologic carbon sequestration sites. Energy Procedia 1, 1925-1932.

Gale, J., Davison, J., 2004. Transmission of CO2 - safety and economic considerations. Energy 29, 1319-1328.

Hill, R., Arnott, A., Hayden, P., Lawton, T., Robins, A., Parker, T., 2011. Evaluation of CFD model predictions of local dispersion from an area source on a complex industrial site. International Journal of Environment and Pollution 44, 173-181.

HSE, H.a.S.C., 2007. List of approved workplace exposure limits (as consolidated with amendments October 2007).

Hsieh, K.-J., Lien, F.-S., Yee, E., 2013. Dense gas dispersion modeling of CO2 released from carbon capture and storage infrastructure into a complex environment. International Journal of Greenhouse Gas Control 17, 127-139.

IPPC, 2005. IPPC Special Report on Carbon Dioxide Capture and Storage. Cambridge University Press, Cambridge, UK/ New York, NY, USA, p. 442.

Kiša, M., Jelemenský, L., 2009. CFD dispersion modelling for emergency preparadnes. Journal of Loss Prevention in the Process Industries 22, 97-104.

Koopman, R.P., Ermak, D.L., Chan, S.T., 1989. A review of recent field tests and mathematical modelling of atmospheric dispersion of large spills of denser-than-air gases. Atmospheric Environment 23, 731-745.

Labovský, J., Jelemenský, L., 2011. Verification of CFD pollution dispersion modelling based on experimental data. Journal of Loss Prevention in the Process Industries 24, 166-177.

Labovský, J., Jelemenský, L., 2010. CFD simulations of ammonia dispersion using "dynamic" boundary conditions. Process Safety \& Environmental Protection: Transactions of the Institution of Chemical Engineers Part B 88, 243-252.

Launder, B.E.S.D.B., 1972. Lectures in mathematical models of turbulence. Academic Press, London; New York.

Lipponen, J., Burnard, K., Beck, B., Gale, J., Pegler, B., 2011. The IEA CCS technology roadmap: one year on. Energy Procedia 4, 5752-5761.

Liu, X., Godbole, A., Lu, C., Michal, G., Venton, P., 2014. Source strength and dispersion of CO2 releases from high-pressure pipelines: CFD model using real gas equation of state. Applied Energy $126,56-68$. 
Mazzoldi, A., 2009. Leakage and atmospheric dispersion of CO2 associated with carbon capture and storage projects. University of Nottingham, Nottingham, UK.

Mazzoldi, A., Hill, T., Colls, J.J., 2008. CFD and Gaussian atmospheric dispersion models: A comparison for leak from carbon dioxide transportation and storage facilities. Atmospheric Environment 42, 8046-8054.

Mazzoldi, A., Hill, T., Colls, J.J., 2011. Assessing the risk for CO2 transportation within CCS projects, CFD modelling. International Journal of Greenhouse Gas Control 5, 816-825.

McBride, M.A., Reeves, A.B., Vanderheyden, M.D., Lea, C.J., Zhou, X.X., 2001. Use of advanced techniques to model the dispersion of chlorine in complex terrain. Process Safety and Environmental Protection 79, 89-102.

Mocellin, P., Vianello, C., Maschio, G., 2015. Carbon capture and storage hazard investigation: numerical analysis of hazards related to dry ice bank sublimation following accidental carbon dioxide releases. Chemical Engineering Transactions 43, 1897-1902.

OSHA, 1989. Carbon dioxide, industrial exposure and control technologies for OSHA. Department of Labor, Washington DC, U.S.

Scargiali, F., Grisafi, F., Busciglio, A., Brucato, A., 2011. Modeling and simulation of dense cloud dispersion in urban areas by means of computational fluid dynamics. Journal of Hazardous Materials 197, 285-293.

Sini, J.-F., Anquetin, S., Mestayer, P.G., 1996. Pollutant dispersion and thermal effects in urban street canyons. Atmospheric Environment 30, 2659-2677.

Sklavounos, S., Rigas, F., 2004. Validation of turbulence models in heavy gas dispersion over obstacles. Journal of Hazardous Materials 108, 9-20.

Tauseef, S.M., Rashtchian, D., Abbasi, S.A., 2011. CFD-based simulation of dense gas dispersion in presence of obstacles. Journal of Loss Prevention in the Process Industries 24, 371-376.

Tola, V., Pettinau, A., 2014. Power generation plants with carbon capture and storage: A technoeconomic comparison between coal combustion and gasification technologies. Applied Energy 113, 1461-1474.

Vianello, C., Macchietto, S., Maschio, G., 2012. Conceptual models for CO2 release and risk assessment: a review. Chemical Engineering Transactions 26, 573-578.

Witlox, H.W.M., 2006. Data review and Phast analysis (discharge and atmospheric dispersion) for BP DF1 $\mathrm{CO}_{2}$ experiments. DNV Software, London, UK.

Xing, J., Liu, Z., Huang, P., Feng, C., Zhou, Y., Zhang, D., Wang, F., 2013. Experimental and numerical study of the dispersion of carbon dioxide plume. Journal of Hazardous Materials 256-257, $40-48$. 
Figures

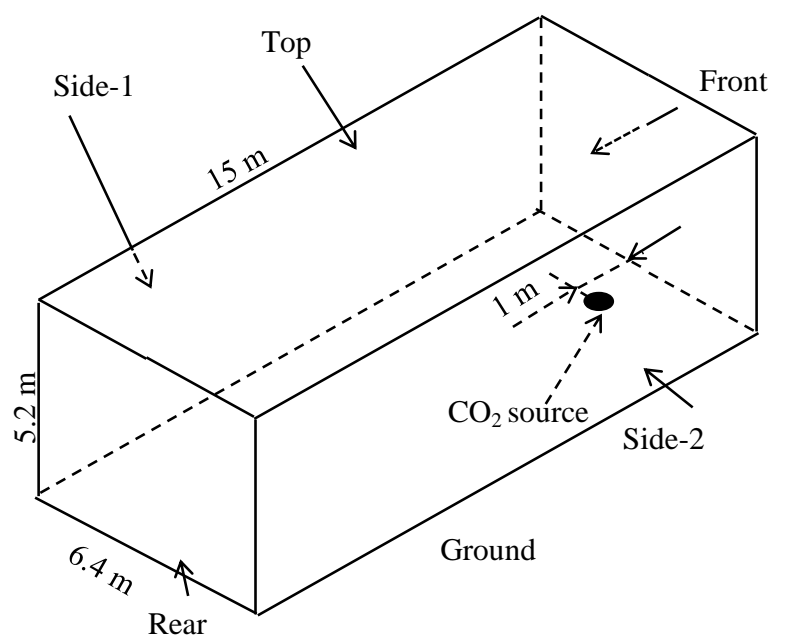

Fig. 1 . Schematic of the computational domain

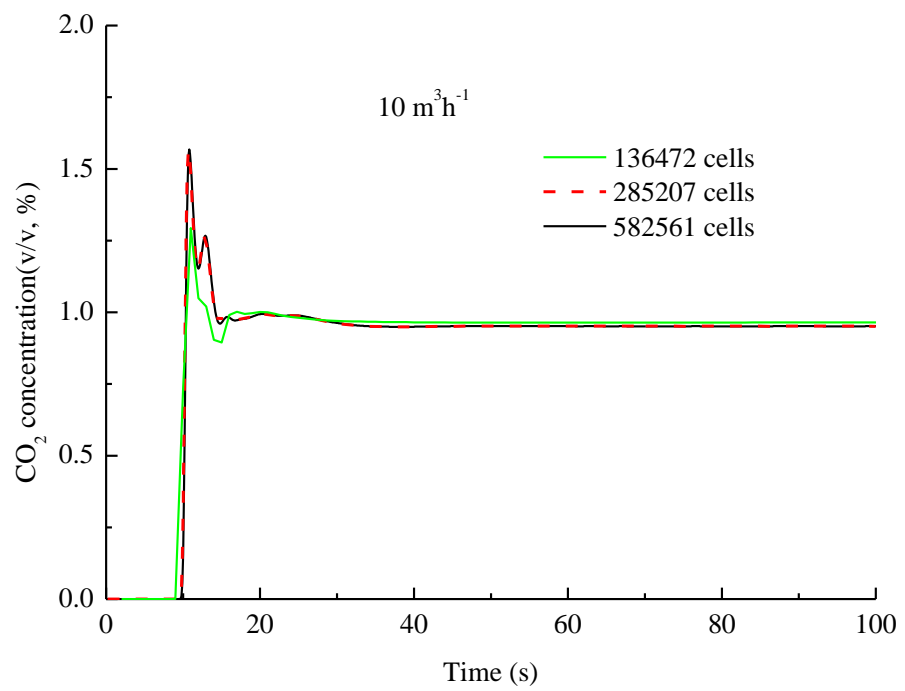

Fig. 2 Grid independence analysis 

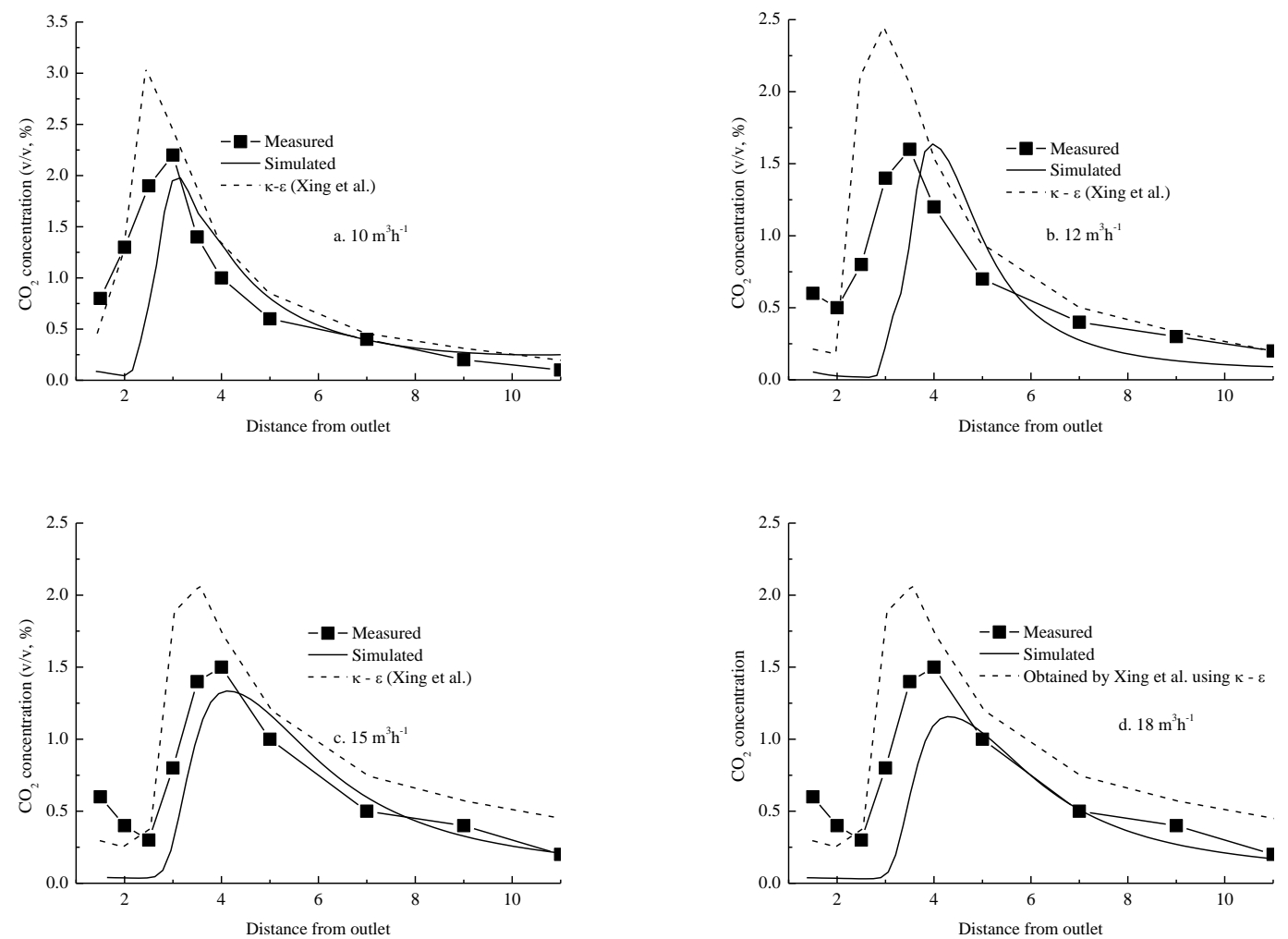

Fig. 3. Ground level $\mathrm{CO}_{2}$ concentration along the centreline
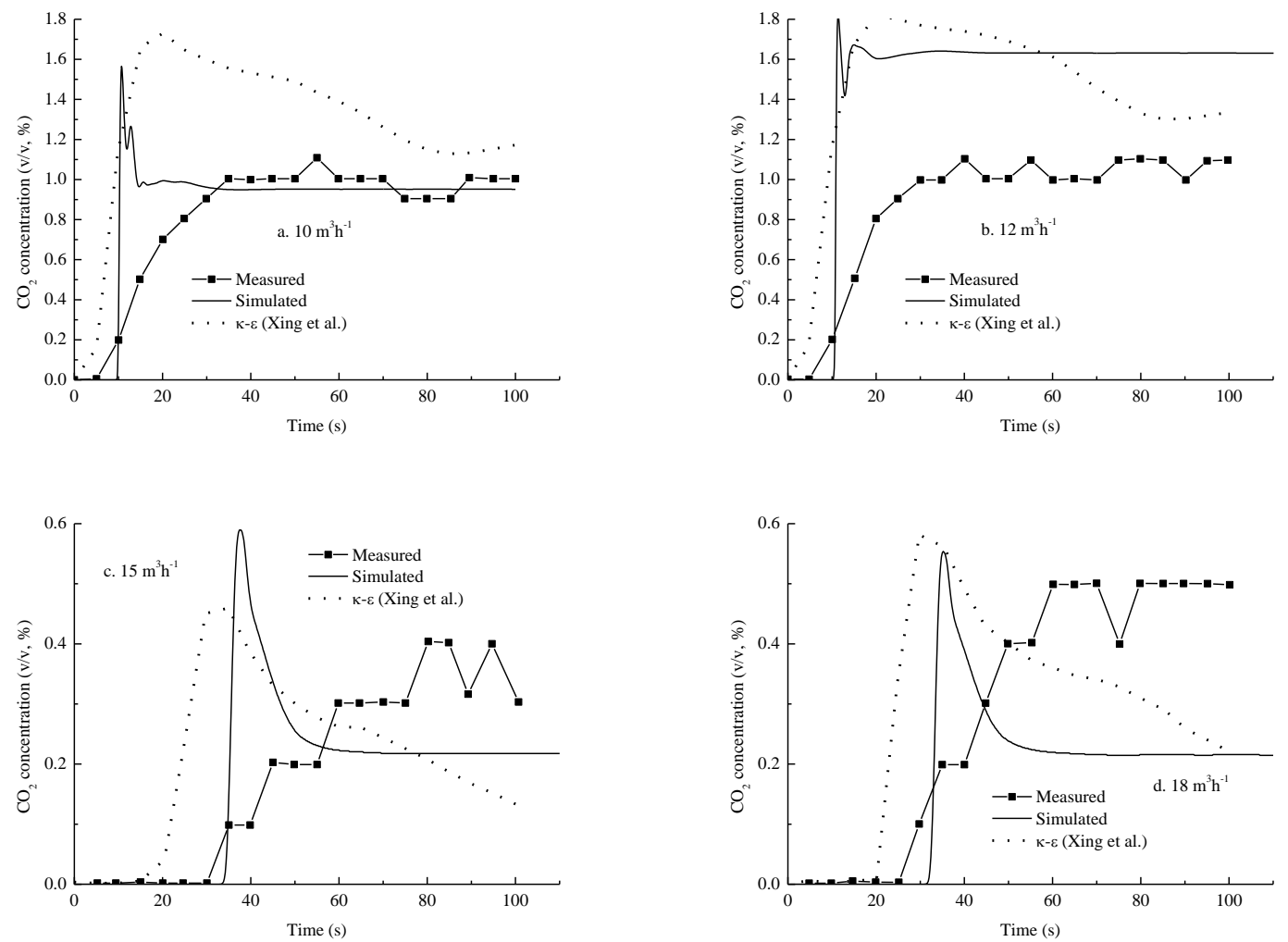

Fig.4. $\mathrm{CO}_{2}$ concentration time history at selected points: (a) $(4,0,0)\left(10 \mathrm{~m}^{-3} \mathrm{~h}^{-1}\right)$, (b) $(4,0,0)\left(12 \mathrm{~m}^{-3} \mathrm{~h}^{-1}\right),(\mathrm{c})(9,0,0)\left(15 \mathrm{~m}^{-}\right.$ 


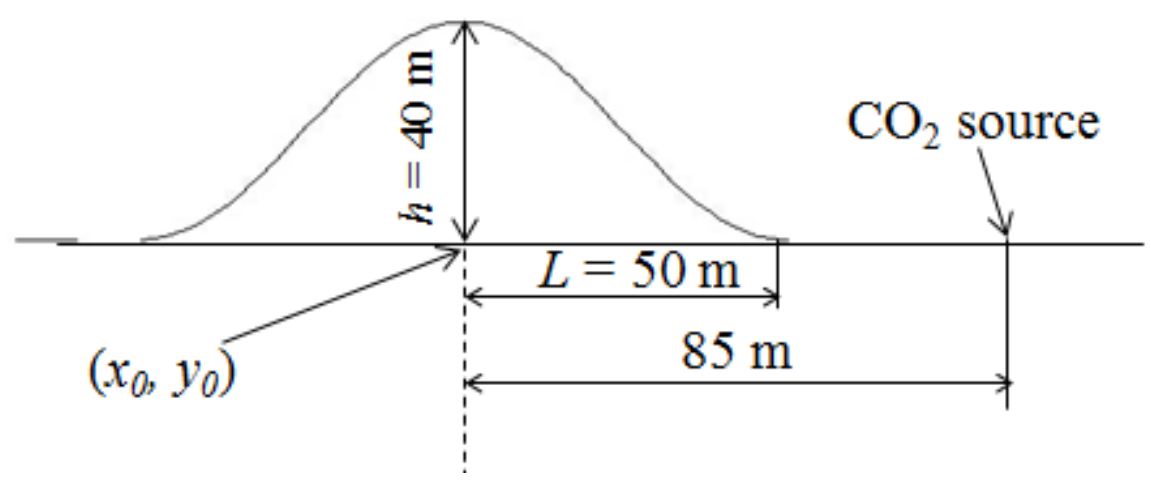

Fig.5. Side view of the hill in Terrain A

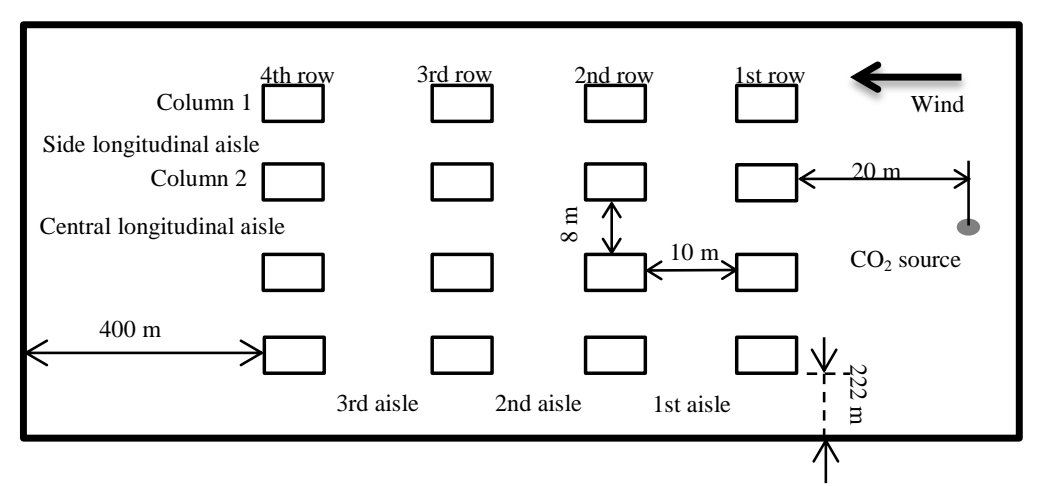

a. Top view

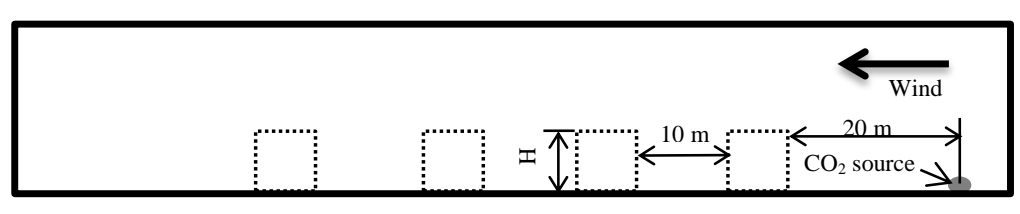

b. Side view

Fig. 6. Top and side view of the urban area in Terrain B (not in proprotation with the simulation domain) 


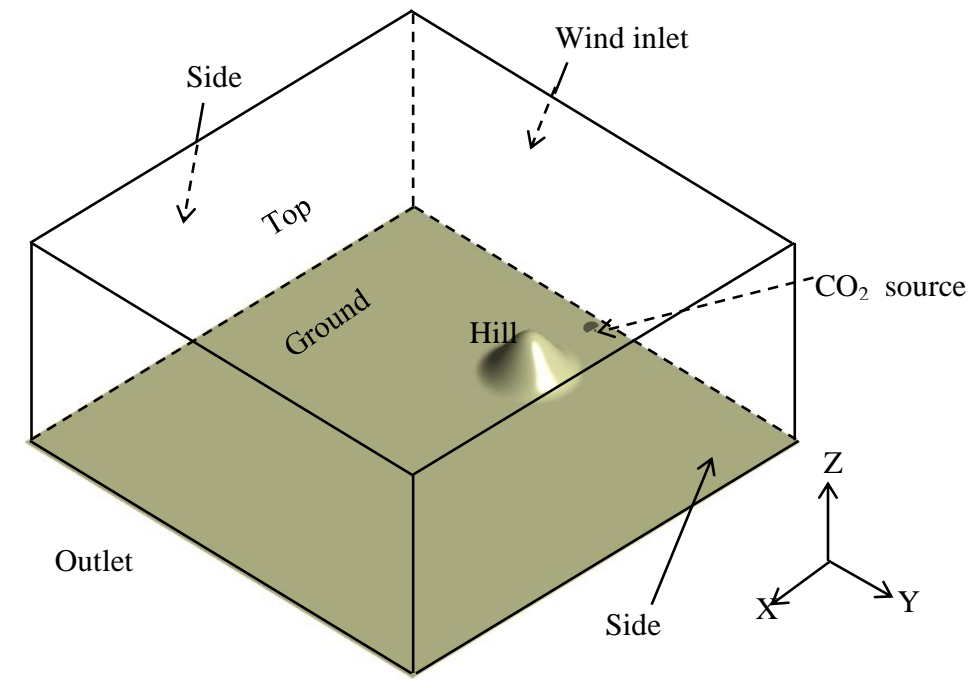

Fig. 7. Computational domain for Terrain A

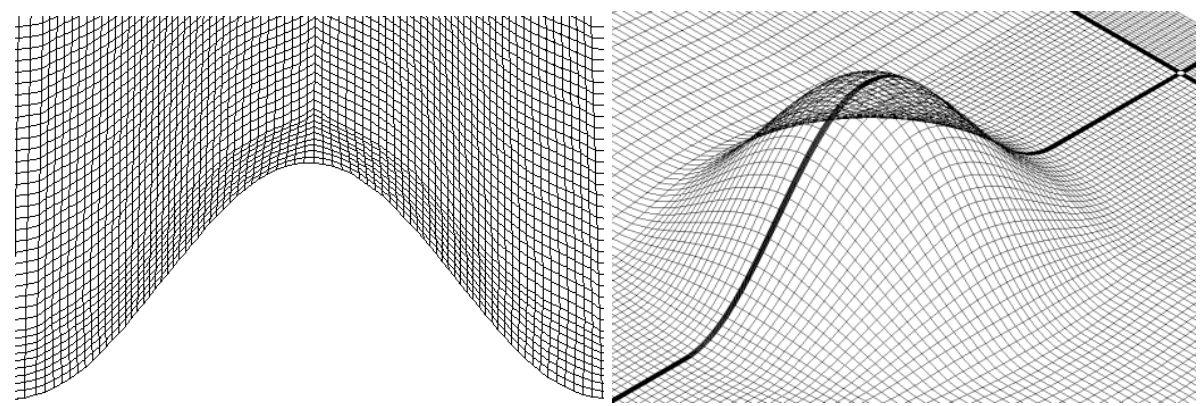

Fig. 8. Sketch of mesh on the symmetry plane and ground near $\mathrm{CO}_{2}$ source and hill(Terrain $\left.\mathrm{A}\right)$

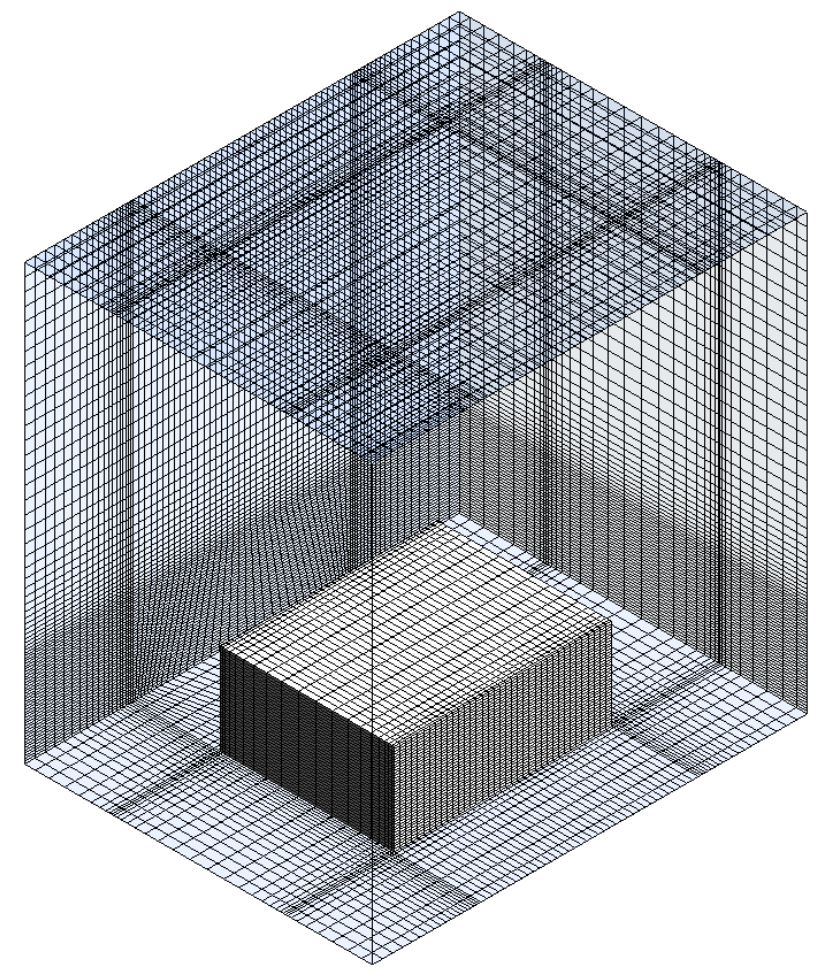


Fig. 9. Typical mesh around a building for Terrain B
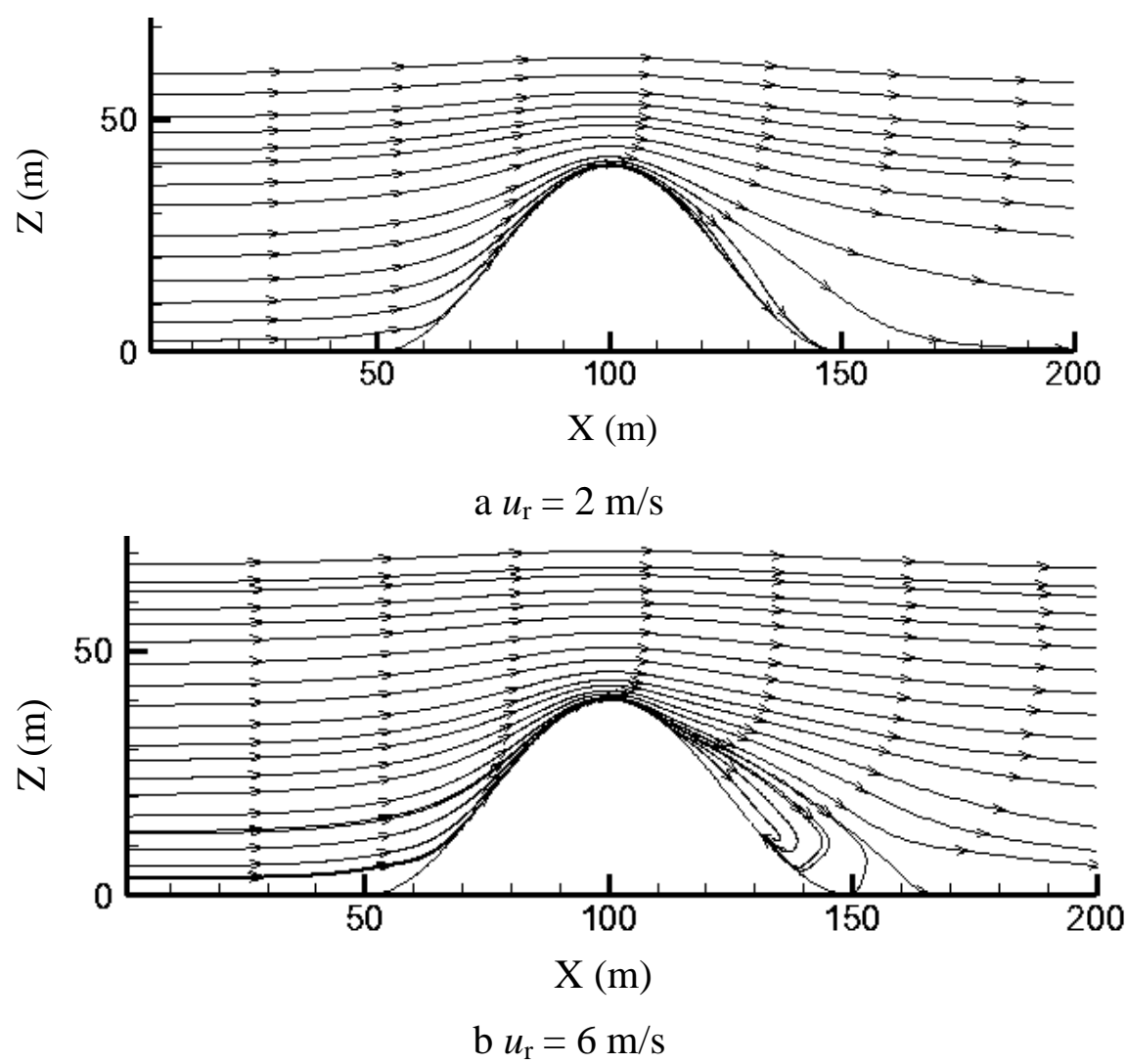

Fig. 10. The streamline around the hill in the symmetry plane in Terrain A

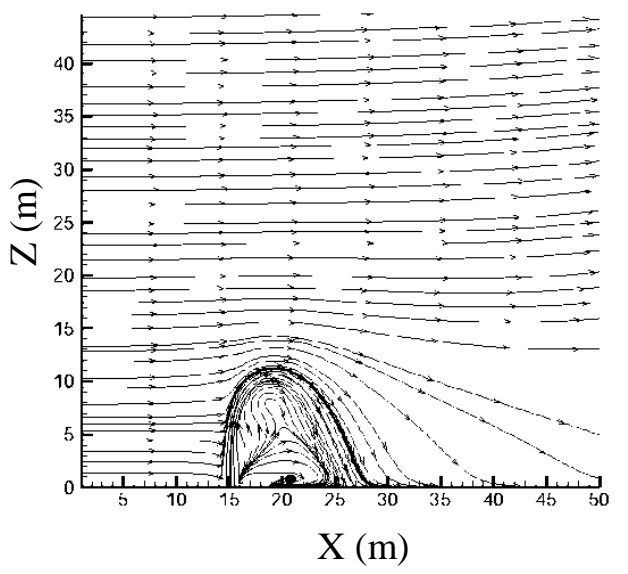

a. $v_{\text {source }}=10 \mathrm{~m} \mathrm{~s}^{-1}$

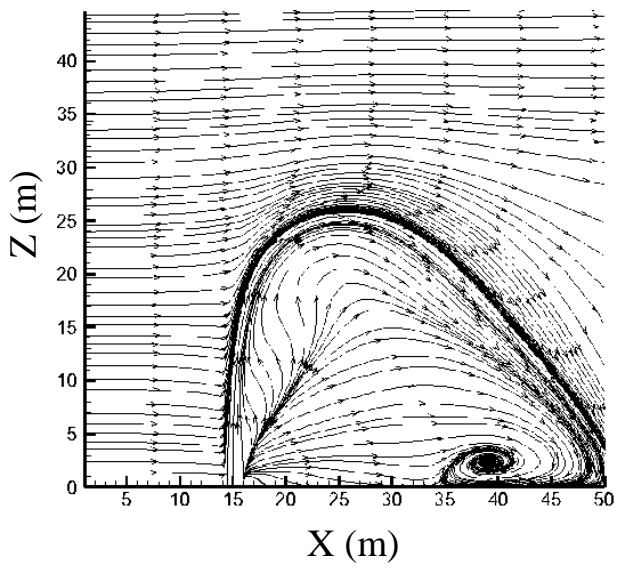

b. $v_{\text {source }}=20 \mathrm{~m} \mathrm{~s}^{-1}$

Fig. 11. The streamline near the source 


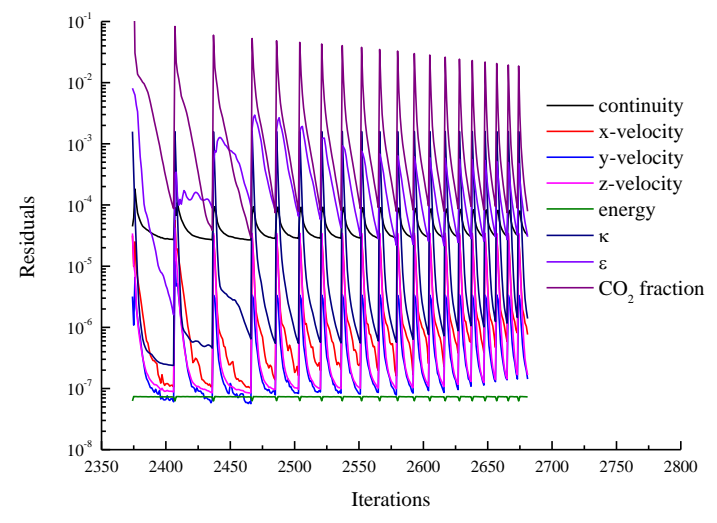

Fig. 12. Convergence histories of flow variables - Terrain A $\left(u_{r}=2 \mathrm{~m} \mathrm{~s}^{-1}, v_{\text {source }}=10 \mathrm{~m} \mathrm{~s}^{-1}\right)$
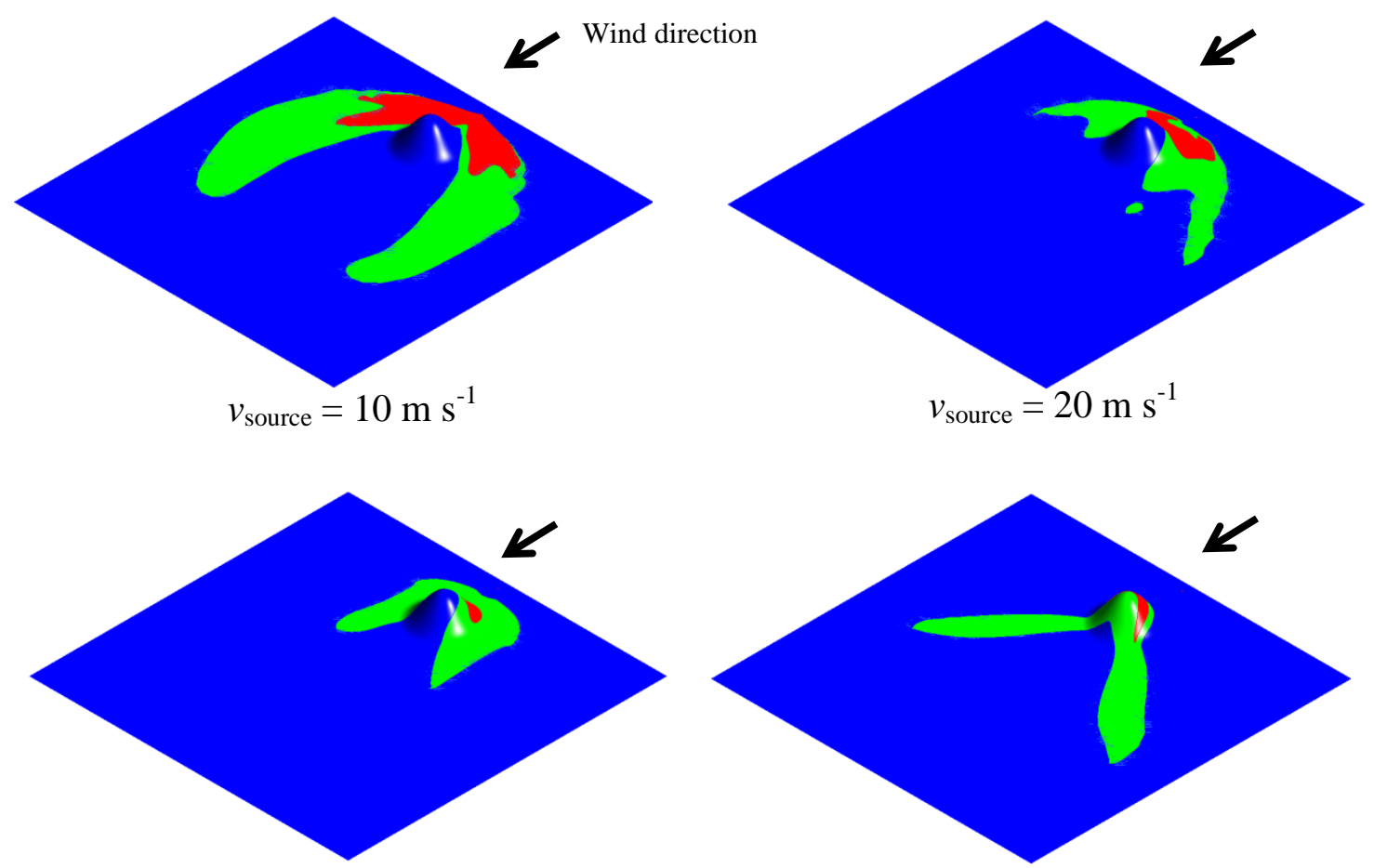

$$
v_{\text {source }}=30 \mathrm{~m} \mathrm{~s}^{-1}
$$$$
v_{\text {source }}=40 \mathrm{~m} \mathrm{~s}^{-1}
$$

Fig. 13. Contours of $\mathrm{CO}_{2}$ concentration at ground level: red contour: $>4 \%$ and green contour: $1.5 \%$ to $4 \%\left(v_{\text {wind }}=2 \mathrm{~m} \mathrm{~s}^{-1}\right)$ 

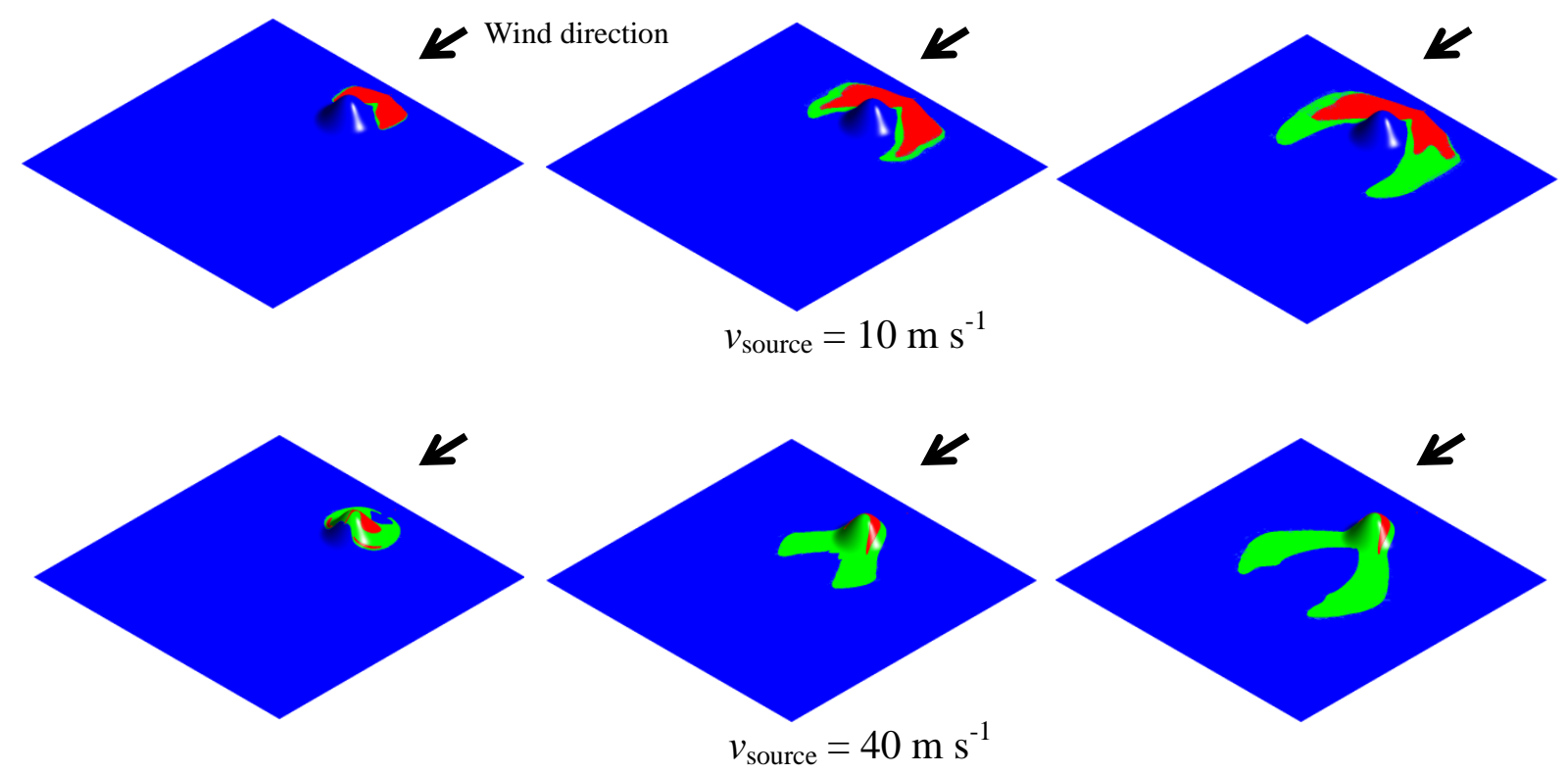

$$
t=50 \mathrm{~s}
$$$$
t=100 \mathrm{~s}
$$$$
t=150 \mathrm{~s}
$$

Fig. 14. The $\mathrm{CO}_{2}$ concentration contours on the ground at different times: red contour $->4 \%$ and green contour $-1.5-4 \%$ $\left(v_{\text {wind }}=2 \mathrm{~m} \mathrm{~s}^{-1}\right)$

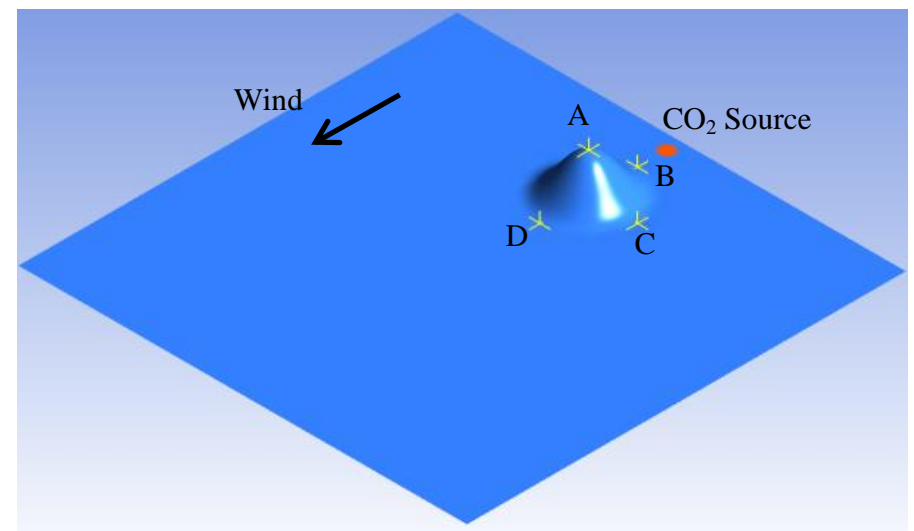

Fig. 15. The diagram of the monitored point locations
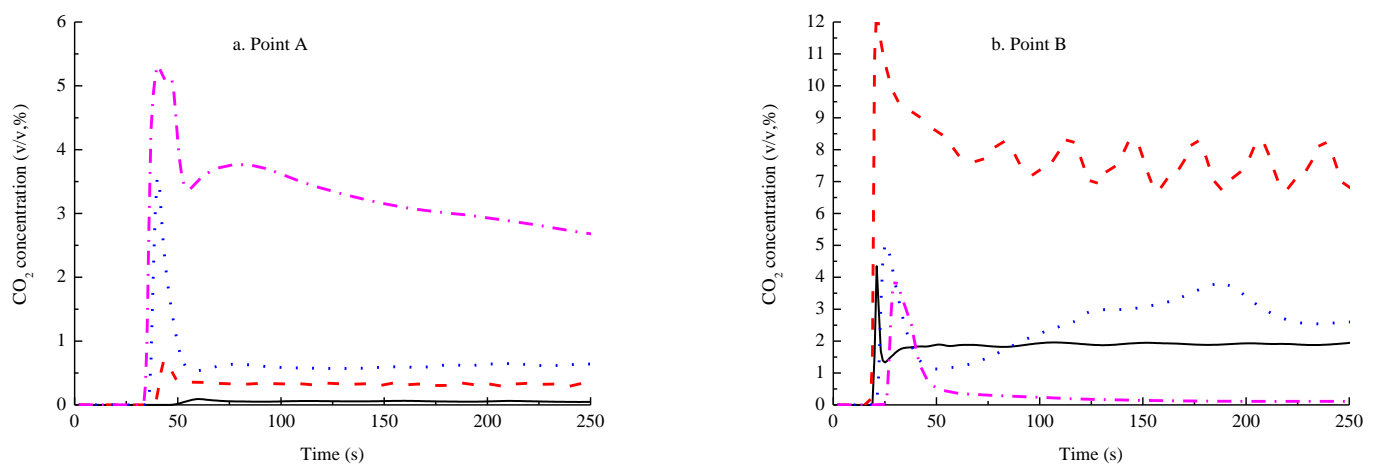

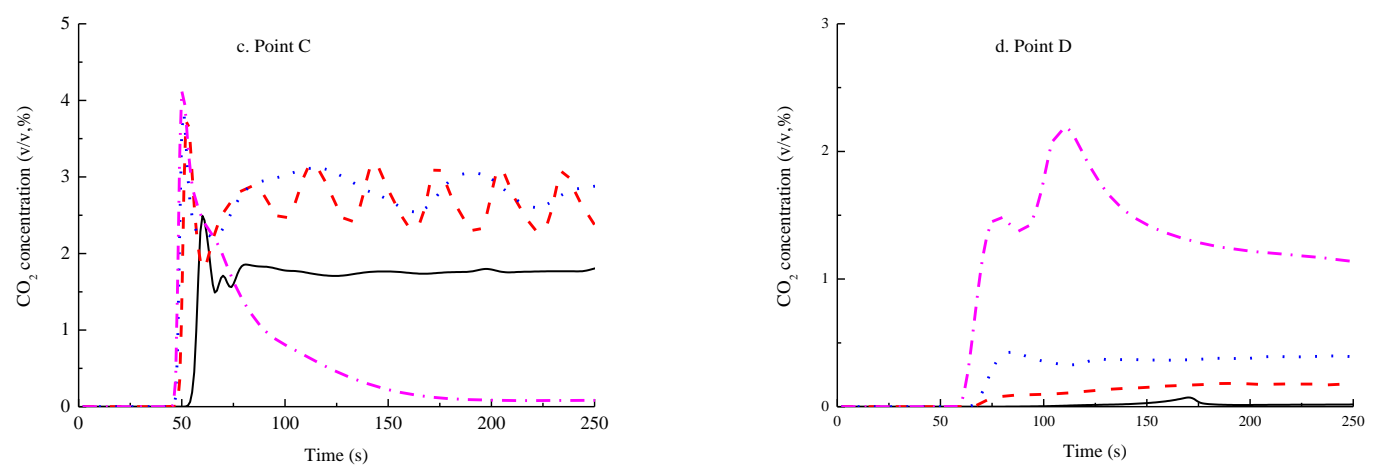

Fig. 16. The time-varying $\mathrm{CO}_{2}$ concentration at different monitor points $\left(-v_{\text {source }}=10 \mathrm{~m} \mathrm{~s}^{-1} ;---v_{\text {source }}=20 \mathrm{~m} \mathrm{~s}^{-1} ;---\right.$ $\left.v_{\text {source }}=30 \mathrm{~m} \mathrm{~s}^{-1} ;-\cdots v_{\text {source }}=40 \mathrm{~m} \mathrm{~s}^{-1}\right)$
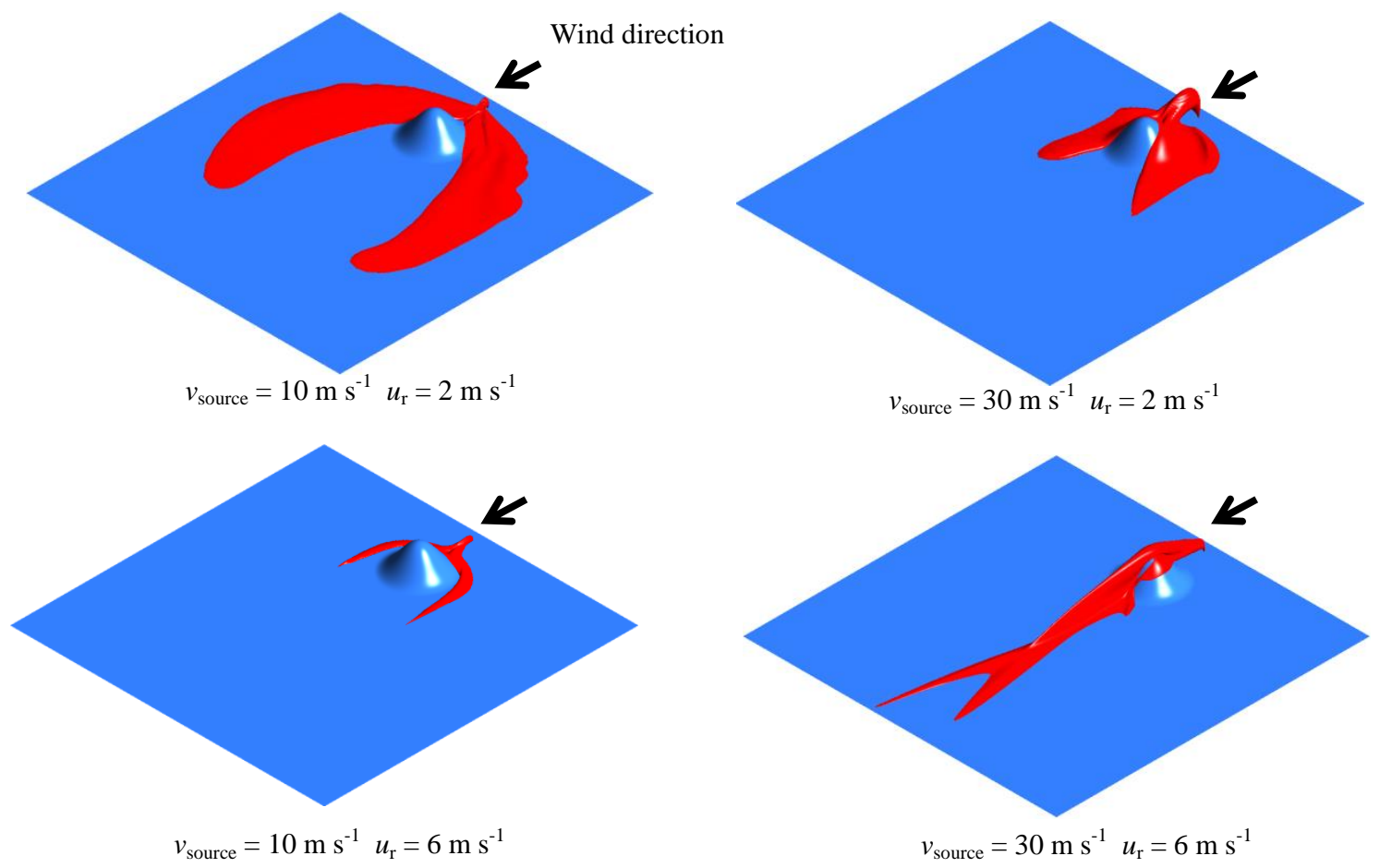

Fig . 17. Iso-surface of gas cloud at concentration level of $1.5 \%$ for various release velocities and wind velocities 


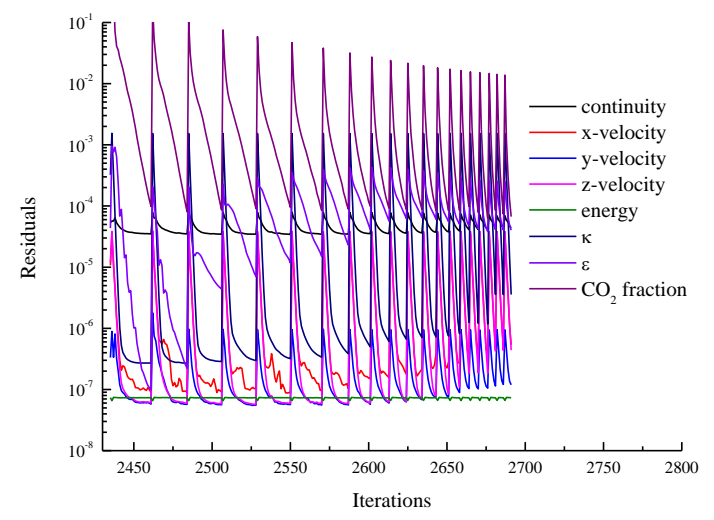

Fig. 18. Convergence histories of flow variables - Terrain $\mathrm{B}\left(\mathrm{H}=4.2 \mathrm{~m}, u_{r}=2 \mathrm{~m} \mathrm{~s}^{-1}\right)$
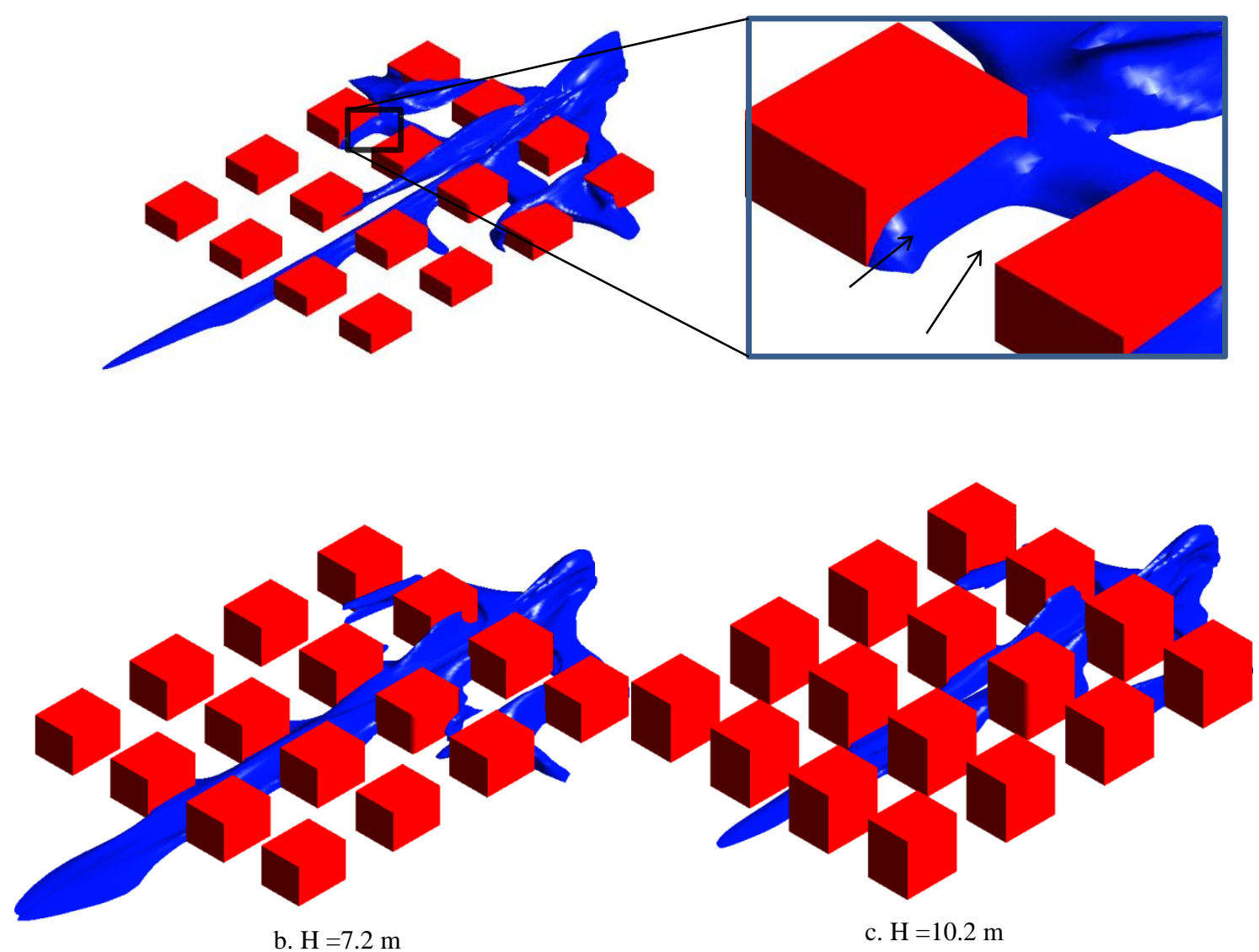

Fig. 19. Iso-surface of $1.5 \% \mathrm{CO}_{2}$ concentration, $300 \mathrm{~s}$ after the release

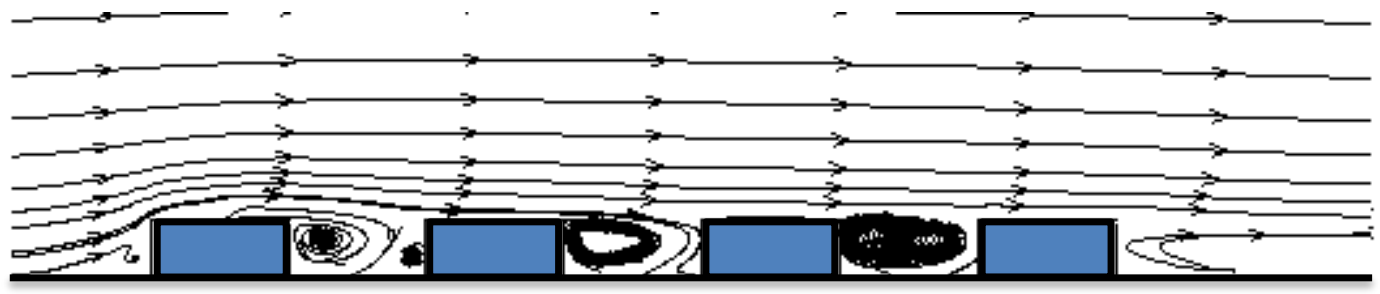


Fig. 20. The streamline $\left(\mathrm{H}=4.2 \mathrm{~m}, u_{r}=2 \mathrm{~m} \mathrm{~s}^{-1}\right)$ at the middle section of the first column buildings

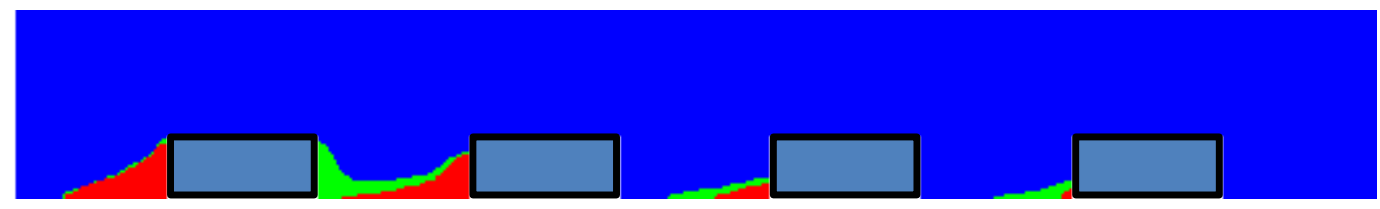

Fig. 21. Contours of $\mathrm{CO}_{2}$ concentration in the middle section of the first column buildings: $>1.5 \%$ (red contour) and $1 \%$ $1.5 \%$ (orange contour) $\left(\mathrm{H}=4.2 \mathrm{~m}, u_{r}=2 \mathrm{~m} \mathrm{~s}^{-1}\right)$

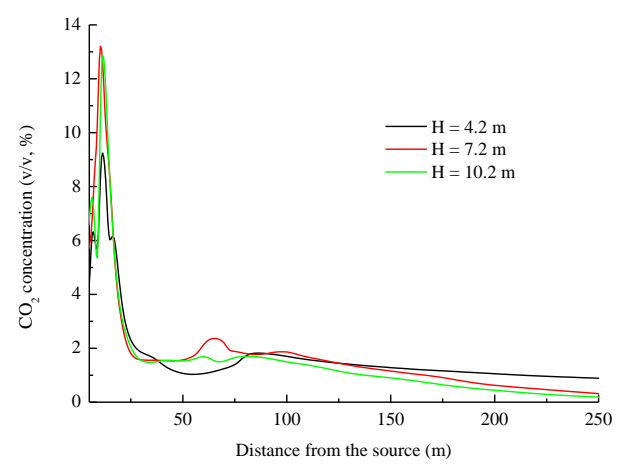

Fig. 22. The maximum concentration (v/v, \%) of $\mathrm{CO}_{2}$ along the downwind distance for different building height

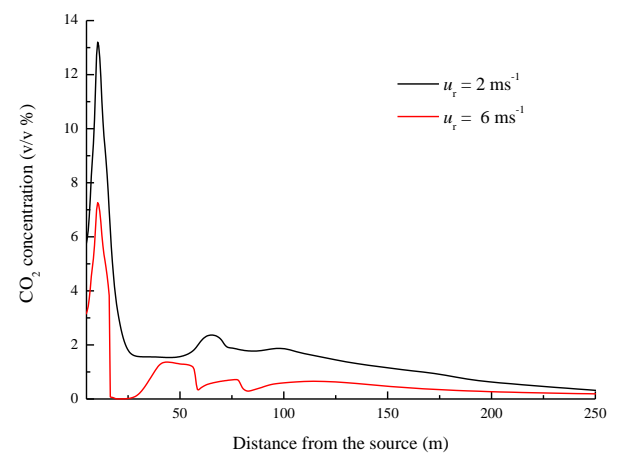

Fig. 23. The maximum concentration (v/v, \%) of $\mathrm{CO}_{2}$ along the downwind distance for different weather condition 


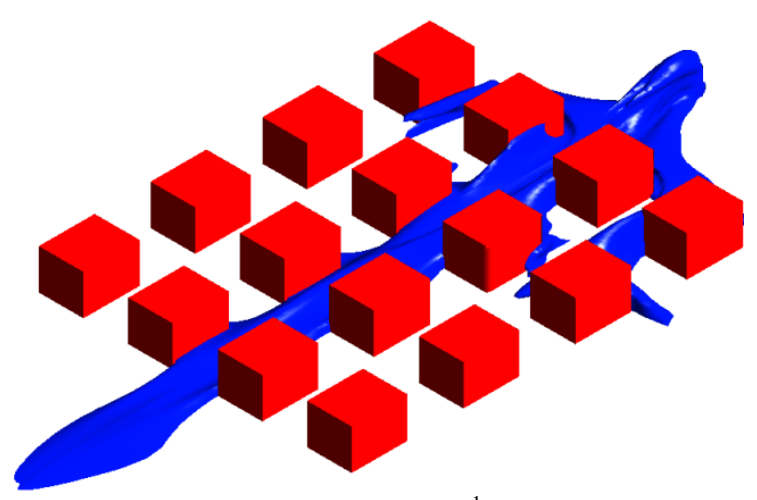

a. $u_{\mathrm{r}}=2 \mathrm{~m} \mathrm{~s}^{-1}$

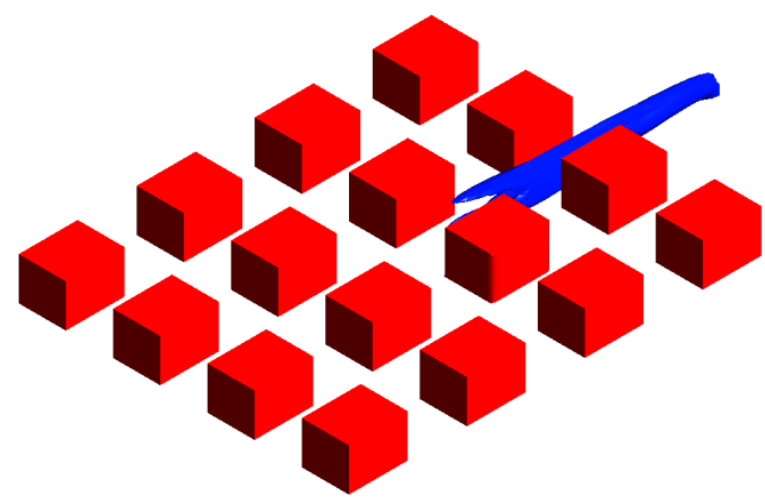

b. $u_{\mathrm{r}}=6 \mathrm{~m} \mathrm{~s}^{-1}$

Fig. 24. Isosurface of $1.5 \% \mathrm{CO}_{2}$ concentration, $300 \mathrm{~s}$ after the release 